\title{
Internal curing of alkali-activated fly ash-slag pastes using superabsorbent polymer
}

\author{
Wenlin Tu ${ }^{\text {a }}$, Yu Zhu ${ }^{\text {a }}$, Guohao Fang ${ }^{\text {a }}$, Xingang Wang ${ }^{\text {, }}$, Mingzhong Zhang a,* \\ ${ }^{a}$ Advanced and Innovative Materials (AIM) Group, Department of Civil, Environmental and Geomatic \\ Engineering, University College London, London WC1E 6BT, UK \\ ${ }^{b}$ School of Civil Engineering and Architecture, Nanchang University, Nanchang 330031, China
}

Abstract: To mitigate autogenous shrinkage that may cause early-age cracking of alkali-activated fly ash-slag (AAFS) concrete, internal curing using superabsorbent polymers (SAP) is employed in this study. AAFS pastes with different SAP dosages (0-0.5\%) and slag replacement ratios to fly ash (15-30\%) are investigated. Experimental results indicate that with the addition of SAP workability of fresh paste is improved while compressive strength is comparatively reduced. As SAP dosage increases from $0.2 \%$ to $0.5 \%$, chemical shrinkage and autogenous shrinkage of AAFS pastes are reduced by around $18 \%$ to $45 \%$ and $76 \%$ to $85 \%$, respectively. Internal curing of SAP is found to lower the heat peak and shift the peak to the right. This indicates the slower hydration rate corresponding to the lower chemo-mechanical deformation (chemical shrinkage), which contributes to the mitigation of autogenous shrinkage. Therefore, internal curing by means of SAP is an efficient method for mitigating autogenous shrinkage in AAFS pastes.

Keywords: Alkali activated concrete (D); Shrinkage (C); Workability (C); Compressive strength (C); Pore size distribution (B)

\section{Introduction}

Ordinary Portland cement (OPC) concrete is the most widely used construction material due to its high performance in terms of workability, compressive strength and cost [1]. However, the growing demand of OPC poses great challenges to concrete industry because of its large carbon emissions [2]. This motivates researchers for seeking suitable alternatives to OPC, and alkali-activated concrete is considered as a potential alternative by utilising industry by-products such as fly ash (FA) and ground granulated blast-furnace slag (GGBS) [3-5]. Although alkali-activated concrete shows comparable engineering properties as OPC concrete, critical concerns have been raised that the alkali-activated fly ash (AAF) concrete requires elevated temperature curing to improve early-age strength [1]. Whereas the alkali-activated slag (AAS) system has rapid setting time and relatively lower workability than OPC [6]. In order to conquer these limitations, alkaliactivated fly ash-slag (AAFS) blended system has recently attracted increasing attention due to its potential ability to achieve superior engineering properties under ambient curing condition [7-9].

Up to now, most of previous studies of AAFS mixtures have focused on the mechanical properties and microstructure [10-12] while the shrinkage behaviour has not been extensively studied. Shrinkage is an important property as it can induce cracks and reduce concrete durability. Shrinkage occurs as a reduction in volume of the concrete due to either drying or the chemical reaction taken place in the system. The common types of shrinkage consist of chemical and autogenous shrinkage in early age and drying shrinkage in the long term. Chemical shrinkage results from the negative balance between the total volume of initial products and the volume of reactants during hydration [13]. Autogenous shrinkage is defined as the unrestrained

\footnotetext{
* Corresponding author. Tel: +44 (0)20 7679 7299; E-mail address: mingzhong.zhang@ucl.ac.uk (M. Zhang)
} 
deformation at constant temperatures, with no water exchange to the external environment after the fresh paste has set and a rigid skeleton begins to develop [14]. In contrast, drying shrinkage is a long-term shrinkage associated with the deformation due to the loss of capillary water [13]. Regarding AAS system, Thomas et al. [15] observed AAS concrete activated by sodium silicate solution has nearly a doubled chemical shrinkage than OPC concrete, which is consistent with the finding by Ye et al. [16] that AAS system has a significantly higher drying shrinkage compared to OPC system. Regarding AAFS system, latest study by Lee et al. [17] demonstrated that the chemical shrinkage of AAFS paste is lower than that of OPC paste, whereas the autogenous and drying shrinkage are higher. To avoid early-age and long-term cracking, taking curing methods to mitigate various types of shrinkage of AAFS pastes, where there is still a lack of systematic studies, is in urgent need.

In general, various curing methods including external and internal curing are applied to reduce shrinkage of concrete by maintaining the relative humidity. The internal curing method has better effects by adding materials with a high water absorption capacity, which can gradually release water during concrete hardening, such that additional water is supplied to the surrounding matrix once self-desiccation occurs, which can then eliminate shrinkage and stimulate further reaction [18-21]. Lightweight aggregate and superabsorbent polymer (SAP) have been commonly used as internal curing agents in previous research on internal curing of concrete. Among them, SAP shows superior absorption and desorption capacity, allowableness of free design of form and size of concrete composite, resistance of concrete to chloride penetration and lower cost [18,22-24].

SAP proposed by Jensen in 2001 [25] has a cross-linked structure, which absorbs water up to 500 times of its own weight [26]. After the addition of water into dry SAP particles, a swollen hydrogel is formed [13]. During the swelling process, the volume of SAP increases with formation of cavities filled with water. The additional water stored in SAP is released to the surroundings during concrete hardening while leaving those cavities as empty pores at later stages of hydration [27]. Consequently, the strength development of mixtures containing SAP is affected due to those macro voids [28]. Liu et al. [18] explored the effect of SAP on mitigation of shrinkages in high strength OPC concrete and found that SAP significantly reduced autogenous shrinkage and drying shrinkage with the dosage around $0.3 \%$ to $0.9 \%$. It was also reported that the addition of SAP in high performance OPC concrete leads to a reduced shrinkage [16,26,27,29]. Fernando et al. [30] partially replaced OPC with slag in mortars and found that mortars with SAP have reduced autogenous shrinkage, especially when slag content is high. Oh and Choi [20] and Song et al. [21] estimated the effect of internal curing by SAP in AAS mortars and both reached a conclusion that SAP is an effective internal curing agent resulting in large reduction of shrinkages with comparative decrease in compressive strength. Up to now, however, the potential mitigation of shrinkages in AAFS system with SAP and corresponding mechanisms have not been explored, which would hinder a wider application of AAFS concrete in industry.

This study therefore aims to investigate the performance of SAP as an internal curing agent in terms of reducing the chemical and autogenous shrinkage of AAFS pastes at $48 \mathrm{~h}$, while maximally maintaining the fresh and mechanical properties of AAFS pastes cured at ambient temperature. The effects of SAP dosages ranging from $0 \%$ to $0.5 \%$ of binder mass with $25 \%$ slag content are of interest and the optimum SAP dosage is then to be applied with different slag contents, i.e., 15\%, 20\% and 30\% of binder mass. Firstly, workability, 
setting time and compressive strength of AAFS pastes are tested to investigate the effect of SAP on basic properties of AAFS pastes. Then, the effect of SAP on mitigation of shrinkages including chemical shrinkage and autogenous shrinkage in AAFS pastes is estimated in the first $48 \mathrm{~h}$ after casting. In addition, the reaction process and microstructure of AAFS with and without SAP is further characterised with the help of isothermal conduction calorimetry (ICC) and mercury intrusion porosimetry (MIP) tests, respectively. Finally, the internal relative humidity (RH) test is carried out to further analyse the internal curing effect of SAP on AAFS pastes.

\section{Experimental program}

\subsection{Raw materials}

Class F FA, GGBS, alkaline activator solution, superplasticisers (SPs) and SAP were used in this study. The FA (average particle size $=26.81 \mu \mathrm{m})$ and slag (average particle size $=14.77 \mu \mathrm{m}$ ) were combined as binder, the chemical compositions and particle size distribution of which are listed in Table 1 and Fig. 1, respectively. $10 \mathrm{M}$ of sodium hydroxide ( $\mathrm{SH}$ ) and sodium silicate (SS) with $31.1 \mathrm{wt} \% \mathrm{SiO}_{2}$ and $12.5 \mathrm{wt} \% \mathrm{Na}_{2} \mathrm{O}$ were used as alkali-activators. The molecular ratio of $\mathrm{SiO}_{2}$ to $\mathrm{Na}_{2} \mathrm{O}$ of SS is 2.58 . The SPs with density of $1.08 \mathrm{~kg} / \mathrm{l}$ and $\mathrm{pH}$ value ranging from 4 to 5 supplied by Sika group was used. The specific gravity of each ingredient is shown in Table 2.

The SAP (AQUASORBTM 3005 S) used in this study is supplied by SNF, UK. It is a cross-linked copolymer or acrylamide and potassium acrylate with irregular particle shape (particle size $<300 \mu \mathrm{m}$ ). Typical characteristics of this SAP product are shown in Table 3. There is an indication that the absorption potential of SAP in synthetic pore fluids is much lower than that in water due to high alkaline environment. The SEM image of SAP particles is illustrated in Fig. 2. It is noticeable that SAP particles are irregular and mostly elongated with a large size variation.

\subsection{Determination of SAP absorption}

The absorption capacity of SAP in the pore solution was generally determined by the 'tea bag' method from previous studies. Schröfl et al. [31] demonstrated the procedure by adding different amounts of water to the solution. The portion of mixed solution absorbed by $1 \mathrm{~g} \mathrm{SAP}$ was determined from measurements of mass disparity between dry and wetted SAP in the solution after 2, 4, 6, 8, 10, 15, $20 \mathrm{~min}$ and then finished at 70 min with 10 min interval, as shown in Fig. 3 [32]. According to the development of SAP sorption in pore solution in time, the maximum sorption is reached within $10 \mathrm{~min}$, which is about $14 \mathrm{~g} / \mathrm{g}$ SAP. This is a theoretical SAP sorption capacity in the static solution, with possible discrepancies compared to the required internal curing water [33], which included the dispersion of SAP particles, formation of agglomerate and crushing of swollen SAP particles [27,34,35]. Mechtcherine et al. also revealed that the sorption process in tea bags was faster than that in fresh matrix [36].

Considering the SAP absorption in a mixing condition, workability test was adopted by many researchers $[27,33]$. To maintain the same flow of SAP mixtures in contrast to the control mixture without SAP addition, Mönnig [27] introduced an approach to compare flowability of mixtures with varying internal curing water. Based on previous studies on the amount of additional water, the suggested range is from $10 \mathrm{~g} / \mathrm{g}$ SAP to 15 g/g SAP $[20,26,37,38]$. The measured flowability of AAFS pastes with different water content in time is shown in Fig. 4. The mixtures with more additional water have greater flow values immediately after mixing. 
Regarding the mixture with $10 \mathrm{~g} / \mathrm{g}$ SAP, the workability drops rapidly after $10 \mathrm{~min}$, resulting in a lower value than the control mixture after $20 \mathrm{~min}$, which can be attributed to the absorption of SAP from alkali-activated solution, due to limited internal curing water supply. The mixture with $12.5 \mathrm{~g} / \mathrm{g}$ SAP has the similar trend with that of the plain mixture, in which the flow values are at a similar level in comparison with others at 40 min. When adding $15 \mathrm{~g} / \mathrm{g}$ SAP internal curing water to the matrix, the flow values are much higher than those of the control mixture in time. Therefore, in this study, the optimum amount of additional water of $12.5 \mathrm{~g} / \mathrm{g}$ SAP was determined by examining the flow as a function of time, which is the most similar to that of the plain mixture without SAP.

\subsection{Mix proportions}

A series of AAFS pastes with mix proportions suggested by our previous research [9] were studied here, i.e., slag content of $25 \%$ of binder mass, alkali-activator/binder ratio of 0.4 and $1 \%$ by binder mass addition of superplasticiser for mixtures 1 (S0.0) to 5 (S0.5). The internal curing water of $12.5 \mathrm{~g} / \mathrm{g}$ SAP was used in the mix design. S0.0 to S 0.5 contain different SAP dosages, from $0 \%$ to $0.5 \%$ by binder mass. GGBS contents of $15 \%, 20 \%$ and $30 \%$ were applied to mixture $6(\mathrm{G} 15), 7(\mathrm{G} 20)$ and $8(\mathrm{G} 30)$, respectively, with replication of other compositions of mixture $3(\mathrm{~S} 0.3 / \mathrm{G} 25)$ for comparative purposes. All mixture proportions are shown in Table 4. Fig. 5 shows the used mixing procedures in this study for mixtures with a low SAP fraction $(<0.6 \%$ by binder mass) [27]. Dry SAP powder was added after the first $30 \mathrm{~s}$ to improve dispersibility.

\subsection{Test methods}

\subsubsection{Workability}

The workability of AAFS pastes was tested by conducting flow table test following ASTM C1437-01 [39]. The flow value was measured by means of a flow mould with $50 \mathrm{~mm}$ height, $70 \mathrm{~mm}$ top opening and $100 \mathrm{~mm}$ bottom opening, placed on the flow table. After filling the mould with paste, the mould was lifted away, and the table was immediately dropped 25 times in $15 \mathrm{~s}$ at a constant frequency. The two perpendicular measurements of spread diameter were taken and recorded. Flow was reported to the nearest $1 \%$.

\subsubsection{Setting time}

The initial and final setting time of all paste mixtures was measured by Vicat needle according to ASTM C19113 [40]. The setting time measurement started once alkaline activator was added into the binder and measurements were taken every $10 \mathrm{~min}$.

\subsubsection{Compressive strength}

The compressive strength tests were carried out using a multifunctional computerised control console machine in accordance to BS EN 12390-3:2009 [41]. Each cube sample with the dimension of $50 \times 50 \times 50 \mathrm{~mm}$ was exposed to compression with a loading rate of $1800 \mathrm{~N} / \mathrm{s}$ and peak sensitivity of $10 \mathrm{~N}$ until failure. The test was performed with regards to all mix samples cured at 1, 3, 7, 14 and $28 \mathrm{~d}$ under constant $20{ }^{\circ} \mathrm{C}$ and $50 \pm 1 \%$ relative humidity. For each compression test, three cubes were crushed. The strength was recorded to the nearest $0.1 \mathrm{MPa}$ and reported by taking the average of three cubes.

\subsubsection{Chemical shrinkage}

Chemical shrinkage tests were performed using dilatometry method suggested by ASTM C1608-12 [42]. After mixing, each paste sample of approximately $20 \mathrm{~g}$ binder (excluding SAP) was placed in a container. The 
container was immediately filled with de-ionised water and a measuring pipette was inserted tightly into the container. The chemical shrinkage, regarded as the volume change of water in pipette is continuously recorded for a period of $48 \mathrm{~h}$.

\subsubsection{Autogenous shrinkage}

Autogenous shrinkage tests were conducted using linear measurements by monitoring the dimension change of the paste samples cast in the rigid mould. It is more preferable compared to volumetric measurements, in which the volume change is determined, because the factors such as thermal dilation and setting time are included in the slab test for a more realistic material behaviour [43]. Fang et al. [44] compared the contact and non-contact methods of linear measurements and concluded that the non-contact method using laser sensors is more suitable as it enables the determination of autogenous shrinkage from the initiation status with a stable and accurate result. An autogenous measuring apparatus consisting of a $70 \times 70 \times 70 \mathrm{~mm}$ inner size PVC mould with sealed cover and a plastic envelope with two reflecting plates. The AAFS paste was immediately placed into the envelope that was oiled and placed into the PVC mould beforehand. It was then sealed and placed in the chamber with steady environment $\left(20^{\circ} \mathrm{C}\right.$ and $\left.40 \% \mathrm{RH}\right)$. Once the autogenous shrinkage takes place in paste samples, a force could be induced, which drags the reflecting plates in the horizontal direction [44]. The autogenous shrinkage corresponding to the horizontal movement of reflection plates was then measured using laser sensors. The data were automatically logged on a computer for $48 \mathrm{~h}$ with a time interval of $0.2 \mathrm{~s}$. For each mixture, three duplicated autogenous shrinkage tests were carried out and an averaged value was taken to reduce random errors [44].

\subsubsection{Isothermal conduction calorimetry}

The reaction process was characterised through ICC by measuring the heat of reaction continued for $48 \mathrm{~h}$ in a TAM Air heat conduction calorimeter. The calorimeter contains 8 measuring channels in a maintained constant temperature. Each channel consists of a chamber of reference and a chamber available for the sample to be tested. The pastes were made from $600 \mathrm{~g}$ binder and appropriate quantity of alkaline activator, superplasticiser and SAP according to relative mix proportions. Each paste specimen was mixed following the specified mixing procedure to ensure a homogeneous distribution of SAP particles. Samples of $5 \mathrm{~g}$ for each individual mixture were then taken out and transferred into calorimeter sample bottles. The bottles were immediately sealed and placed into the chamber. Measurements of heat difference between samples and the reference were taken and the hydration heat evolution rate was continuously monitored respect to time.

\subsubsection{Mercury intrusion porosimetry}

The pore structure of paste samples at $48 \mathrm{~h}$ after casting were characterised by MIP. The specimens were crushed into granular forms, submerged in organic solvent Acetone for $2 \mathrm{~d}$ and then vacuum dried for $3 \mathrm{~d}$ in order to stop chemical reaction.

\subsubsection{Internal relative humidity}

The internal RH of AAFS pastes at $48 \mathrm{~h}$ after casting was measured by humidity data logger (Onset HOBO UX100-003, MicroDAQ.com. Ltd, USA). The data logger was placed inside the sealed paste mould, which was protected by a hollow cylindrical plastic tube. The internal RH of AAFS pastes was measured and logged every $1 \mathrm{~min}$ for $48 \mathrm{~h}$. 


\section{Results}

\subsection{Workability}

Fig. 6 shows the changes in workability of all mixtures in terms of flow values (i.e. spread diameter) with time. It can be observed that the flowability varies from S0.0 to S0.5 immediately after mixing. The initial flow value increases with increasing SAP amount in the mixture since SAP dose not reach its maximum absorption capacity during that period of time after mixing. The evolution of flow values in time is similar for all five mixtures and the flow values finally decrease to around $70 \mathrm{~mm}$. However, the time taken to reach the lowest flowability is different from S0.0 to S0.5. This can be ascribed to the incorporation of more SAP and water content, which forms a less cohesive tissue in the matrix and thus contributes to the variation of flow values for different mixtures.

\subsection{Setting time}

Fig. 7 shows the initial and final setting times of AAFS pastes. In general, the plain mixture (S0.0) has a shorter setting time in contrast with others (see Fig. 7a). There is a conspicuous trend that both initial and final setting times are delayed when incorporating SAP to AAFS pastes. S0.5 achieves the highest initial and final setting time of $147 \mathrm{~min}$ and $180 \mathrm{~min}$, respectively. The addition of internal curing water could delay the chemical reaction in pastes due to the formation of swollen SAP hydrogel and further hydration reaction [26]. The postulation implies that there could be a potential change of AL/B ratio caused by available water inside SAP particles for involvement in the chemical reaction [20].

The relationship between setting time and slag content is illustrated in Fig. 7b. Generally, both initial and final setting times decrease when slag content increases. The highest initial and final setting times are from G15, i.e. $257 \mathrm{~min}$ and $310 \mathrm{~min}$ respectively. It is shown that the change of setting time is more significant at lower levels of slag content, since the initial setting time decreases dramatically to $130 \mathrm{~min}$ (G20). This reveals that the inclusion of slag can speed up the rate of chemical reaction. Fly ash as a pozzolanic material has a slower reaction rate at ambient temperature compared to slag in particular during the early age [45]. Therefore, the mixtures containing more slag content can achieve shorter setting times.

\subsection{Compressive strength}

Compressive strength is one of the most essential mechanical properties of concrete, which can directly indicate if there is any concomitant loss of physical properties of mixtures with an addition of SAP in AAFS pastes. The compressive strength development from $1 \mathrm{~d}$ to $28 \mathrm{~d}$ is demonstrated in Fig. 8. Regarding basic construction purposes and corrosion protection of concrete reinforcement, the compressive strength of concrete at $28 \mathrm{~d}$ should exceed $28 \mathrm{MPa}$ and $35 \mathrm{MPa}$ respectively according to ACI 318M-05 [44,46].

As seen in Fig. 8a, a lower compressive strength is generated with SAP addition. S0.2 to S0.4 can achieve compressive strength of more than $35 \mathrm{MPa}$ at $28 \mathrm{~d}$, therefore are acceptable regarding to the above-mentioned criteria. Generally, water inside the swollen SAP is involved in further chemical reaction, which could result in the development of air voids that influences the strength evolution and reduces the stiffness of matrix [20,21]. The strength loss from S0.0 to S0.2 is approximately 20\%, which is much smaller than that of around 50\% for AAS mortars reported in [21]. However, the loss disparity of compressive strength with an increase of SAP dosage seems relatively inconsequential regarding S0.2 to S0.4, whereas it becomes more pronounced with 
0.5\% SAP inclusion. This implies that there may be a combined effect between strength lost and gained, as SAP particles could arguably play the role as crack arrestors to improve compressive strength.

Fig. 8 b shows that the $28 \mathrm{~d}$ compressive strengths of G25 and G30 exceed $35 \mathrm{MPa}$. For every $5 \%$ increment of slag content, the compressive strength increases about $7 \mathrm{MPa}$ at $28 \mathrm{~d}$. The inclusion of slag can speed up the rate of chemical reaction, which can be attributed to the presence of calcium bearing compound in slag. The calcium alumino-silicate hydrate (C-A-S-H) gel may be constituted in AAFS system, which attributes to the growth of compressive strength [45]. In addition, as slag content increases, fly ash and slag particles would be packed better in terms of densification and permeability because of small particle size of slag [37]. Therefore, the chemical reaction inside paste matrix could be more efficient for strength development.

\subsection{Chemical shrinkage}

Chemical shrinkage is recognised as one of the main causes of early-age autogenous shrinkage resulting from volumetric difference between chemical reactants and products in matrix. The previous studies of chemical shrinkage in OPC system reported that the inclusion of SAP increased chemical shrinkage since the additional water promoted further hydration [18]. Thus, more capillary voids were formed, which contributed to a greater shrinkage. However, the AAFS system is activated by strong alkaline, which is different from the hydration process of OPC. The results of chemical shrinkage with SAP addition are shown in Fig. 9.

Fig. 9a demonstrates the effect of SAP dosage on chemical shrinkage. It can be seen that the chemical shrinkage is obviously reduced when SAP dosage increases, which is contradicted with the results obtained in OPC system [18]. The trend shows a rapid increase of chemical shrinkage during the first $10 \mathrm{~h}$, followed by a dormant period with slower growth rate until $30 \mathrm{~h}$. Then it enters an acceleration period until $48 \mathrm{~h}$. When SAP dosage increases from $0.2 \%$ to $0.5 \%$, the chemical shrinkage is reduced by around $18 \%$ to $45 \%$ as compared with the plain mixture. The mitigation of chemical shrinkage in AAFS system could be ascribed to the internal curing effect of SAP, since the additional water released from swollen SAP particles can impede the early-age chemical reaction and refine the pore structure [47].

The effect of slag content on the first $48 \mathrm{~h}$ chemical shrinkage is shown in Fig. 9b. For AAFS pastes with the same SAP dosage, the chemical shrinkage increases with increasing slag content. The lowest and highest chemical shrinkage at $48 \mathrm{~h}$ after mixing is $0.023 \mathrm{~mL} / \mathrm{g}$ and $0.04 \mathrm{~mL} / \mathrm{g}$, respectively. It can be noted that the chemical shrinkage of G20 slightly exceeds that of G25 at the beginning, which shows an instability of reaction rate inside the AAFS matrix with SAP during the first few hours.

\subsection{Autogenous shrinkage}

Fig. 10a shows the autogenous shrinkage development with different SAP dosages within $48 \mathrm{~h}$. Generally, the autogenous shrinkage increases rapidly during the first few hours, after which the shrinkage slows down and maintains a dormant period. The results reveal a substantial autogenous shrinkage reduction of $76-85 \%$ with 0.2-0.5\% SAP addition compared to S0.0, which is in good agreement with the previous research [21]. This could be ascribed to the decrease of self-desiccation caused by a lower level of induced capillary pressure during the internal curing process [37]. Moreover, the increase of SAP dosage could result in a greater zone inside matrix that is benefited from the internal curing [21]. 
It can be noted that there are dramatic mitigations of autogenous shrinkage in S0.2 and S0.3, whereas the shrinkage mitigation is less significance when SAP dosage is more than $0.3 \%$. This indicates that an optimum SAP dosage is $0.3 \%$ in terms of shrinkage mitigation efficiency. The addition of SAP as an internal curing agent in AAFS system can mitigate autogenous shrinkage effectively, since the moisture loss can be supplemented and thus the deformation caused by self-desiccation and volume reduction of chemical reactants can be restrained by SAP.

According to Fig. 10b, the trend of shrinkage development is comparatively consistent with that shown in Fig. 10a. With $0.3 \%$ SAP addition, the increase of slag content from $15 \%$ to $30 \%$ leads to a greater shrinkage at $48 \mathrm{~h}$, which is in good agreement with the previous research of AAFS pastes [44]. The maximum shrinkage discrepancy between G15 and G30 is about $1500 \mu \varepsilon$ (see Fig. 10b). This is due to a more rapid chemical reaction of slag as a latent hydraulic material compared with fly ash at the early stage. Therefore, the incorporation of slag can result in the formation of a denser matrix providing with a more violent capillary action, that leads to an increase of autogenous shrinkage [21,37]. However, the fluctuation of shrinkage during the first few hours shown in Fig. 10b represents the potential unstable skeleton of matrix in AAFS system with SAP addition, which can be further corroborated with the ICC results.

\subsection{Isothermal reaction}

As is shown in Fig. 11, the first peak appeared in heat flow curves at the beginning is inconsequential to the actual chemical reaction since it shows a physical phenomenon, whereas the second peak indicated the main reaction of the formation of aluminosilicate gels $[44,48,49]$.

Fig. 11a shows the heat flow of S0.0 to S0.5 as a function of time. S0.0 generates the maximum secondpeak heat flow (around $7.8 \mathrm{~mW} / \mathrm{g}$ ) compared with mixtures with SAP (S0.2 to S0.5). As the SAP dosage increases from $0.2 \%$ to $0.5 \%$, the ultimate heat flow of second peak decreases significantly from $6.04 \mathrm{~mW} / \mathrm{g}$ to $1.08 \mathrm{~mW} / \mathrm{g}$. It is indicated that the inclusion of SAP could impede the early-age chemical reaction of the AAFS pastes by the amount of entrained water. In addition, the acceleration period is retarded from about 1 to $4 \mathrm{~h}$ and shifted to the right, which indicates the deceleration of initial alkali-reaction. This could be attributed to the absorption characteristics of SAP. It was found that besides water, some alkali ions could be absorbed by SAP as well during the first few hours after mixing [50]. The implication is that the concentration of alkaliactivator could be affected by absorption behaviour of SAP, thus leading to delay of the main peak. This testifies with the results of setting time that a longer setting time occurs when SAP dosage increases (see Fig. 7a). However, this is inconsistent with the previous study of AAS system, which stated a discrete relationship between the magnitude of generated heat flow and SAP addition [20]. The could be ascribed to the difference in the early-age chemical reaction of alkali-activated systems with and without the incorporation of fly ash. This can be further investigated through microstructure analysis of the formation of C-N-A-S-H gel regarding the participation of early-age dissolution of fly ash ( $\mathrm{Si}$ and $\mathrm{Al}$ ) and hydration of slag ( $\mathrm{Ca})$ [51]. Furthermore, it is observed that when SAP dosage increases to $0.4-0.5 \%$, a third peak occurs at approximately $7 \mathrm{~h}$ (see Fig. 11a). The maximum heat flow of S0.5 exceeds that of S0.4. This could be explained by the excess internal curing water, which may result in a further hydration with slag. 
Fig. 11b shows ICC results with different slag content from $20 \%$ to $30 \%$. The second peak can be detected at about $2 \mathrm{~h}$ for all three mixtures. The maximum heat flow of second peak increases correspondingly with the increase of slag content from $2.2 \mathrm{~mW} / \mathrm{g}$ to $3 \mathrm{~mW} / \mathrm{g}$. Moreover, a retardation of the main peak can be observed with a decrease of slag content. As mentioned previously, a higher slag content can boost up the reaction rate in AAFS system, since the additional calcium content in the matrix participates in the formation of more amorphous gel [51]. The heat flow, as a presentation of chemical reaction process, can consequently reflect a more violent acceleration period with more slag content. The abnormal phenomenon can also be found in autogenous and chemical shrinkage shown in Figs. 9b and 10b.

\subsection{Pore structure}

The pore size distribution of AAFS pastes at $48 \mathrm{~h}$ is shown in Fig. 12. The volume fractions of both small and large pores become greater with an increase of SAP dosage (see Fig. 12a). The formation of large pores (ranging from 1000-60,000 nm) due to the addition of SAP can result in a coarsening of the pore structure and reduced surface tension, which contribute to the mitigation of drying shrinkage [52,53]. This study also focuses on the variation of small pores ranging from 3-50nm [54], since small pores play a critical role in capillary pressure that causes shrinkage stress [44,55]. The volume fraction of small pores increases from $15.97 \%$ to $31.92 \%$ with SAP inclusion of $0-0.5 \%$, which implies that self-desiccation tends to be more pronounced with increasing SAP dosage, as the capillary force per unit water loss is highly associated with small pores [52]. As seen in Fig. 12b, the volume fraction of small pores decreases from 23.09\% (G30) to $21.12 \%$ (G15) with an increase of slag content, which agrees well with the previous study of AAFS pastes [44]. Fig. 13 shows the porosity of AAFS with various SAP dosages and slag content. There is no conspicuous change of porosity with different SAP dosages, whereas the porosity decreases significantly from $33.68 \%$ to $25.18 \%$ with the increase of slag content from $15 \%$ to $30 \%$.

\subsection{Internal relative humidity}

Fig. 14 shows the evolution of internal RH of AAFS pastes at $48 \mathrm{~h}$. As seen in Fig. 14a, the internal RH of AAFS pastes is improved comparatively from $86.9 \%$ (S0.0) to $90.2 \%$ (S0.5) at $48 \mathrm{~h}$, which reflects the internal curing effect of SAP inside the paste matrix directly since the evolution of self-desiccation is impeded. When increasing SAP dosage to above $0.4 \%$, there is no significant improvement of internal $\mathrm{RH}$, which remains at the level of around $90 \%$. Fig. 14b illustrates the results of AAFS pastes with different slag content. It can be observed that all mixtures follow a similar trend that the internal RH increases rapidly at first followed by a steady period until $48 \mathrm{~h}$, which is higher than $88 \%$.

\section{Discussion}

In order to discuss the general effect of SAP addition on autogenous shrinkage of AAFS, the compensation ratio (CR) is introduced, which is defined as follows [21]:

$C R=\frac{\varepsilon_{0}-\varepsilon_{1}}{\varepsilon_{0}} \times 100 \%$

where $\varepsilon_{0}$ is the autogenous shrinkage of samples without SAP and $\varepsilon_{1}$ is the autogenous shrinkage of samples with SAP.

By calculating CR of autogenous shrinkage at $24 \mathrm{~h}$ and $48 \mathrm{~h}$, the early-age internal curing effect as a function of SAP dosage can be obtained (see Fig. 15). There is a positive nonlinear correlation between CR of 
autogenous shrinkage and SAP dosage, which is in good agreement with the results for AAS system [21]. It can be concluded that an increase of SAP dosage leads to a higher CR. For AAFS with $0.5 \%$ SAP, the CR value reaches $90 \%$, which means that the shrinkage is almost compensated. It is noted that the CR increases rapidly when SAP dosage is up to $0.3 \%$, which indicates that the internal curing effect is more crucial when SAP dosage is increased to $0.3 \%$. The sensitivity of CR to SAP inclusion (i.e. the change of CR per unit SAP dosage) is less significant when the dosage exceeds $0.3 \%$ suggesting that S0.3 is more efficient regarding internal curing effect in this study. However, this relationship is not linearly proportional, which implies that different SAP dosages may be used for internal curing purposes in different mix proportions.

In the first $48 \mathrm{~h}$, the autogenous shrinkage is a physicochemical phenomenon, which combines the chemomechanical deformation recognised as chemical shrinkage ( $0 \mathrm{~h}$ - initial setting time) and the hygro-mechanical deformation due to self-desiccation (final setting time - $48 \mathrm{~h}$ ) [51]. In order to further investigate the effect of SAP in the development of autogenous shrinkage, the mechanisms of internal curing of SAP are discussed below based on chemo-mechanical and hygro-mechanical deformation stages.

The early-age internal curing effect on the manifestation of autogenous shrinkage is explored through the change of chemical shrinkage (see Fig. 16). It is clearly shown that the chemical shrinkage dominates the early-age autogenous shrinkage when the sample is at liquid stage. There is a prominent increase of autogenous shrinkage before initial setting, whereas it reaches a plateau with minor changes as the chemical shrinkage increases after final setting. This is consistent with the prior research on autogenous shrinkage of AAFS system that the chemo-mechanical deformation becomes a minor component of autogenous shrinkage at hardened stage [51]. This trend is obvious for S0.0 and S0.2 (with 0.2\% SAP) but becomes flatter with a less conspicuous acceleration period at the beginning of chemical shrinkage development as SAP dosage increases. This implies that with the addition of SAP the contribution of chemical shrinkage on early-age autogenous shrinkage is impeded by internal curing, and hygro-mechanical deformation may take place particularly at liquid stage. This is consistent with the ICC results shown in Fig. 11a. Regarding the incorporation of slag, Fig. 17 presents the relationship between chemical and autogenous shrinkage for AAFS with varying slag content from 15\% to $30 \%$. The autogenous shrinkage shows a relatively more rapid increase with chemical shrinkage (chemomechanical deformation) for all specimens at liquid stage before initial setting. The increase of autogenous shrinkage is more significant when slag content is higher. This can be mainly attributed to the participation of slag particles at the early-age formation of reaction products as mentioned before.

The cumulative heat is another important parameter related to chemical reaction since it is proportional to the degree of hydration [56]. Hence, the relationship between autogenous shrinkage and heat reaction is investigated considering specimens with and without SAP. In general, the autogenous shrinkage increases substantially with the increase of cumulative heat released due to the internal chemical reaction of AAFS (see Fig. 18). Both results demonstrate an acceleration period at liquid stage, which is followed by a dormant period at transition stage between initial and final setting. However, the sensitivity of autogenous shrinkage to cumulative heat increases again after final setting within the specimen S0.3. This could be ascribed to the mitigation of further hygro-mechanical deformation on autogenous shrinkage, since the internal curing water starts to be released from the swollen SAP at hardened stage. 
The pore structure of studied AAFS pastes at hardened stage shows that the volume fraction of both large and small pores increases significantly with the addition of SAP (see Fig. 12a). The occurrence of large pores indicates a smaller self-desiccation localised by drying, which is consistent with the above discussion. Conversely, the increase of small pores suggests a greater hygro-mechanical deformation. Thus, a higher autogenous shrinkage should be observed in specimens with SAP. However, as seen in Fig. 10a, the plain mixture (S0.0) exhibits the greatest autogenous shrinkage, which reveals that the capillary force induced by small pores may not be the main contributor of autogenous shrinkage at hardened stage in AAFS pastes due to the internal curing effect by SAP. Moreover, the internal RH results shown in Fig. 14a imply that the selfdesiccation inside paste matrix due to water loss is mitigated since there is an improvement of internal RH by about 3\% with incorporation of SAP. Therefore, the postulation is further corroborated that hygro-mechanical deformation gives minor contribution to overall autogenous shrinkage of AAFS pastes with SAP. The alkaline activation in AAFS could also affect the mechanisms of autogenous shrinkage. In accordance to our previous study on AAFS pastes, the formation of aluminosilicate gel is unstable, so that this gel may experience a packing process causing a denser and steadier state of C-A-S-H gel [44,57]. The addition of SAP could influence this rearrangement by releasing internal curing water and thus lead to the refinement of pore structure. The increase of SAP dosage implies a relatively richer water environment at hardened stage as well as more tightly bonded water in the gel and more smaller pores that are formed during the evolution of reaction products [58-60]. Therefore, it can be concluded that the internal curing effect of SAP on mitigating autogenous shrinkage is a combination of different mechanisms in AAFS system.

Overall, the contribution of each stage to the total autogenous shrinkage of AAFS with different SAP dosages at $48 \mathrm{~h}$ is shown in Fig. 19. 77.5\% of autogenous shrinkage in the control mixture (S0.0) is generated before initial setting indicating the importance of chemo-mechanical deformation at liquid stage, which is consistent with the results shown in Fig. 16. As SAP dosage increases, the fraction of autogenous shrinkage at hardened stage is increased up to $72.2 \%$ (S0.4), which is much higher than that for S0.0, i.e., 19.4\%. This implies that the hygro-mechanical deformation at hardened stage contributes the most to autogenous shrinkage of AAFS pastes with increasing dose of SAP. Therefore, it can be concluded that the addition of SAP has a significant effect on mitigating early-age chemo-mechanical deformation and thus resulting in a mitigation of early-age autogenous shrinkage.

\section{Conclusions}

In this study, the feasibility of using SAP as internal curing agents to mitigate the autogenous shrinkage in AAFS pastes with various slag content cured at ambient temperature while maintaining the acceptable engineering properties including workability, setting time and compressive strength is investigated. Based on the experimental results, the main conclusions can be drawn as follows:

- Setting time of AAFS pastes increases with the addition of SAP, while the compressive strength is reduced with increasing SAP dosage due to the additional water incorporated in the mixtures with SAP. The compressive strength is decreased by $20 \%$ when $0.2 \%$ SAP (by binder mass) is added into the mixture and tends to be stable when the SAP dosage is in the range between $0.2 \%$ and $0.4 \%$. 
- Chemical shrinkage and autogenous shrinkage of AAFS pastes are significantly reduced by the addition of SAP, while internal relative humidity is improved. As SAP dosage increases from $0.2 \%$ to $0.5 \%$ the chemical shrinkage is reduced by around $18 \%$ to $45 \%$, while the autogenous shrinkage is decreased by approximately $76 \%$ to $85 \%$.

- The addition of SAP lowers the heat peak of the AAFS pastes and leads to a shift of the peak to the right, which corresponds to the slower hydration rate and lower chemical shrinkage resulting in a reduction in autogenous shrinkage.

- The optimum dosage of SAP is found to be $0.3 \%$ for AAFS pastes considering autogenous shrinkage as well as other engineering properties such as workability, setting time and compressive strength.

- Internal curing by means of SAP is an effective strategy to mitigate the autogenous shrinkage in AAFS pastes. From the relationship between autogenous shrinkage and chemical shrinkage, cumulative heat and setting time it can be found that the addition of SAP impedes chemo-mechanical deformation while releasing internal curing water to compensate the losses due to self-desiccation of AAFS pastes at the early age and thus contributes substantially to mitigation of early-age autogenous shrinkage.

\section{Acknowledgements}

The authors gratefully acknowledge the Engineering and Physical Sciences Research Council (EPSRC) for the financial support for this research (EP/R041504/1). The authors would like to thank Hanson UK and SNF S.A.S for generously providing GGBS and SAP products, respectively. The authors also thank Mr Warren Gaynor and Mr Raman Mangabhai from UCL Laboratory of Advanced Materials and Dr Judith Zhou from UCL Environmental Engineering Laboratory for their help with experiments.

\section{References}

[1] B. Rajini, A.V.N. Rao, Mechanical Properties of Geopolymer Concrete with Fly Ash and GGBS as Source Materials, Int. J. Innov. Res. Sci. Eng. Technol. 03 (2014) 15944-15953.

[2] B. Singh, G. Ishwarya, M. Gupta, S.K. Bhattacharyya, Geopolymer concrete: A review of some recent developments, Constr. Build. Mater. 85 (2015) 78-90.

[3] Z. Shi, C. Shi, J. Zhang, S. Wan, Z. Zhang, Z. Ou, Alkali-silica reaction in waterglass-activated slag mortars incorporating fly ash and metakaolin, Cem. Concr. Res. 108 (2018) 10-19.

[4] J.L. Provis, Alkali-activated materials, Cem. Concr. Res. (2017). in press.

[5] J.L. Provis, A. Palomo, C. Shi, Advances in understanding alkali-activated materials, Cem. Concr. Res. 78 (2015) 110-125.

[6] K. Arbi, M. Nedeljkovic, Y. Zuo, S. Grünewald, A. Keulen, G. Ye, Experimental study on workability of alkali activated fly ash and slag-based geopolymer concretes, Geopolymers Route to Elimin. Waste Emiss. Ceram. Cem. Manuf. ISBN 9781326377328. (2015) 75-78.

[7] X. Fan, M. Zhang, Behaviour of inorganic polymer concrete columns reinforced with basalt FRP bars under eccentric compression: An experimental study, Compos. Part B Eng. 104 (2016) 44-56.

[8] X. Fan, M. Zhang, Experimental study on flexural behaviour of inorganic polymer concrete beams reinforced with basalt rebar, Compos. Part B Eng. 93 (2016) 174-183.

[9] G. Fang, W.K. Ho, W. Tu, M. Zhang, Workability and mechanical properties of alkali-activated fly ash- 
slag concrete cured at ambient temperature, Constr. Build. Mater. 172 (2018) 476-487.

[10] S. Kumar, R. Kumar, S.P. Mehrotra, Influence of granulated blast furnace slag on the reaction, structure and properties of fly ash based geopolymer, J. Mater. Sci. 45 (2010) 607-615.

[11] N.K. Lee, H.K. Kim, I.S. Park, H.K. Lee, Alkali-activated, cementless, controlled low-strength materials (CLSM) utilizing industrial by-products, Constr. Build. Mater. 49 (2013) 738-746.

[12] R. LLOYD, The microstructure of geopolymers synthesised from industrial waste, in: 1st Int. Conf. Eng. Waste Treat., 2005.

[13] L. Stefan, C. Boulay, J.M. Torrenti, B. Bissonnette, F. Benboudjema, Influential factors in volume change measurements for cementitious materials at early ages and in isothermal conditions, Cem. Concr. Compos. 85 (2018) 105-121.

[14] A. (Ed. . Bentur, Report 25: early age cracking in cementitious systems-Report of RILEM technical committee TC 181-EAS: early age cracking shrinkage induced stresses and cracking in cementitious systems., RILEM Pubblications. 25 (2003).

[15] J.J. Thomas, A.J. Allen, H.M. Jennings, Density and water content of nanoscale solid C-S-H formed in alkali-activated slag (AAS) paste and implications for chemical shrinkage, Cem. Concr. Res. 42 (2012) 377-383.

[16]H. Ye, C. Cartwright, F. Rajabipour, A. Radlińska, Effect of drying rate on shrinkage of alkali-activated slag cements, in: Proc. 4th Int. Conf. Durab. Concr. Struct. ICDCS 2014, 2014.

[17] N.K. Lee, J.G. Jang, H.K. Lee, Shrinkage characteristics of alkali-activated fly ash/slag paste and mortar at early ages, Cem. Concr. Compos. 53 (2014) 239-248.

[18] J. Liu, C. Shi, X. Ma, K.H. Khayat, J. Zhang, D. Wang, An overview on the effect of internal curing on shrinkage of high performance cement-based materials, Constr. Build. Mater. 146 (2017) 702-712.

[19] O.M. Jensen, P.F. Hansen, Water-entrained cement-based materials, Cem. Concr. Res. 31 (2001) 647654.

[20] S. Oh, Y.C. Choi, Superabsorbent polymers as internal curing agents in alkali activated slag mortars, Constr. Build. Mater. 159 (2018) 1-8.

[21]C. Song, Y.C. Choi, S. Choi, Effect of internal curing by superabsorbent polymers - Internal relative humidity and autogenous shrinkage of alkali-activated slag mortars, Constr. Build. Mater. 123 (2016) 198-206.

[22] O.M. Jensen, P. Lura, Techniques and materials for internal water curing of concrete, Mater. Struct. 39 (2006) 817-825.

[23]H. Beushausen, M. Gillmer, M. Alexander, The influence of superabsorbent polymers on strength and durability properties of blended cement mortars, Cem. Concr. Compos. 52 (2014) 73-80.

[24] M.T. Hasholt, O.M. Jensen, Chloride migration in concrete with superabsorbent polymers, Cem. Concr. Compos. 55 (2015) 290-297.

[25] R.E. Philleo, Concrete science and reality, in: Mater. Sci. Concr. II, 1991: pp. 1-8.

[26]D. Snoeck, O.M. Jensen, N. De Belie, The influence of superabsorbent polymers on the autogenous shrinkage properties of cement pastes with supplementary cementitious materials, Cem. Concr. Res. 74 
(2015) 59-67.

[27] S. Mönnig, Superabsorbing additions in concrete - applications, modelling and comparison of different internal water sources, PhD thesis, University of Stuattgart, 2009.

[28] Y. Wehbe, A. Ghahremaninezhad, Combined effect of shrinkage reducing admixtures (SRA) and superabsorbent polymers (SAP) on the autogenous shrinkage, hydration and properties of cementitious materials, Constr. Build. Mater. 138 (2017) 151-162.

[29] V. Mechtcherine, M. Gorges, C. Schroefl, A. Assmann, W. Brameshuber, A.B. Ribeiro, D. Cusson, J. Custódio, E.F. Da Silva, K. Ichimiya, S.I. Igarashi, A. Klemm, K. Kovler, A.N. De Mendonça Lopes, P. Lura, V.T. Nguyen, H.W. Reinhardt, R.D.T. Filho, J. Weiss, M. Wyrzykowski, G. Ye, S. Zhutovsky, Effect of internal curing by using superabsorbent polymers (SAP) on autogenous shrinkage and other properties of a high-performance fine-grained concrete: Results of a RILEM round-robin test, Mater. Struct. 47 (2014) 541-562.

[30]F.C.R. Almeida, A.J. Klemm, Efficiency of internal curing by superabsorbent polymers (SAP) in PCGGBS mortars, Cem. Concr. Compos. 88 (2018) 41-51.

[31]C. Schröfl, V. Mechtcherine, M. Gorges, Relation between the molecular structure and the efficiency of superabsorbent polymers (SAP) as concrete admixture to mitigate autogenous shrinkage, Cem. Concr. Res. 42 (2012) 865-873.

[32]C. Schröfl, D. Snoeck, V. Mechtcherine, A review of characterisation methods for superabsorbent polymer (SAP) samples to be used in cement-based construction materials: report of the RILEM TC 260RSC, Mater. Struct. 50(197) (2017) 1-19.

[33] B.J. Olawuyi, W.P. Boshoff, Influence of SAP content and curing age on air void distribution of high performance concrete using 3D volume analysis, Constr. Build. Mater. 135 (2017) 580-589.

[34]D. Cusson, V. Mechtcherine, P. Lura, Application of Super Absorbent Polymers (SAP) in Concrete Construction, RILEM State of the Art Reports 2, 2012. doi:10.1007/978-94-007-2733-5_10.

[35]L.P. Esteves, Recommended method for measurement of absorbency of superabsorbent polymers in cement-based materials, Mater. Struct. 48 (2015) 2397-2401.

[36] V. Mechtcherine, E. Secrieru, C. Schröfl, Effect of superabsorbent polymers (SAPs) on rheological properties of fresh cement-based mortars - Development of yield stress and plastic viscosity over time, Cem. Concr. Res. 67 (2015) 52-65.

[37] J. Liu, Z. Ou, J. Mo, Y. Wang, H. Wu, The effect of SCMs and SAP on the autogenous shrinkage and hydration process of RPC, Constr. Build. Mater. 155 (2017) 239-249.

[38] J. Justs, M. Wyrzykowski, D. Bajare, P. Lura, Internal curing by superabsorbent polymers in ultra-high performance concrete, Cem. Concr. Res. 76 (2015) 82-90.

[39] Astm, Standard Test Method for Flow of Hydraulic Cement Mortar: C1437-01, Standard. (2001) 7-8.

[40] ASTM International, ASTM C191-13 Standard Test Method for Time of Setting of Hydraulic Cement by Vicat Needle, 2013.

[41]BRITISH STANDARDS INSTITUTION, BS EN 12390-3:2009, Test. Hardened Concr. Part 3 Compressive Strength Test Specimens. (2009). 
[42] ASTM Committee C01.31, ASTM C1608-12 Standard Test Method for Chemical Shrinkage of Hydraulic Cement Paste, in: Annu. B. ASTM Stand. 04 (2012) 1-5.

[43]E. Holt, Contribution of mixture design to chemical and autogenous shrinkage of concrete at early ages, Cem. Concr. Res. 35 (2005) 464-472.

[44] G. Fang, H. Bahrami, M. Zhang, Mechanisms of autogenous shrinkage of alkali-activated fly ash-slag pastes cured at ambient temperature within 24 h, Constr. Build. Mater. 171 (2018) 377-387.

[45]P. Nath, P.K. Sarker, Effect of GGBFS on setting, workability and early strength properties of fly ash geopolymer concrete cured in ambient condition, Constr. Build. Mater. 66 (2014) 163-171.

[46] ACI 318M, Building Code Requirements for Structural Concrete and Commentary (ACI 318M-05), Am. Concr. Inst. 2003 (2005) 436.

[47] X. Ma, J. Zhang, J. Liu, Review on superabsorbent polymer as internal curing agent of high performance cement-based material, Kuei Suan Jen Hsueh Pao/Journal Chinese Ceram. Soc. v 43, n 8 (2015) 10991110.

[48] S. Chithiraputhiran, N. Neithalath, Isothermal reaction kinetics and temperature dependence of alkali activation of slag, fly ash and their blends, Constr. Build. Mater. 45 (2013) 233-242.

[49] B. Singh, M.R. Rahman, R. Paswan, S.K. Bhattacharyya, Effect of activator concentration on the strength, ITZ and drying shrinkage of fly ash/slag geopolymer concrete, Constr. Build. Mater. 118 (2016) 171-179.

[50] J. Mo, Z. Ou, X. Zhao, J. Liu, Y. Wang, Influence of superabsorbent polymer on shrinkage properties of reactive powder concrete blended with granulated blast furnace slag, Constr. Build. Mater. 146 (2017) 283-296.

[51] S. Nie, S. Hu, F. Wang, P. Yuan, Y. Zhu, J. Ye, Y. Liu, Internal curing - A suitable method for improving the performance of heat-cured concrete, Constr. Build. Mater. 122 (2016) 294-301.

[52] R.J. Thomas, D. Lezama, S. Peethamparan, On drying shrinkage in alkali-activated concrete: Improving dimensional stability by aging or heat-curing, Cem. Concr. Res. 91 (2017) 13-23.

[53] M. Palacios, F. Puertas, Effect of superplastisizer and shrinkage reducing admixtures on alkali-activated slag pastes and mortars, Cem. Concr. Res. 35 (2005) 1358-1367.

[54]D.H. Everett, Manual of Symbols and Terminology for Physicochemical Quantities and Units, Appendix II: Definitions, Terminology and Symbols in Colloid and Surface Chemistry, Pure Appl. Chem. 31 (1972).

[55] J.J. Thomas, H.M. Jennings, A colloidal interpretation of chemical aging of the C-S-H gel and its effects on the properties of cement paste, Cem. Concr. Res. 36 (2006) 30-38.

[56]E. ichi Tazawa, S. Miyazawa, T. Kasai, Chemical shrinkage and autogenous shrinkage of hydrating cement paste, Cem. Concr. Res. 25 (1995) 288-292.

[57] I. García-Lodeiro, A. Fernández-Jiménez, A. Palomo, Variation in hybrid cements over time. Alkaline activation of fly ash-portland cement blends, Cem. Concr. Res. 52 (2013) 112-122.

[58] B.E.I. Abdelrazig, S.D. Main, D. V. Nowell, Hydration studies of modified OPC pastes by differential scanning calorimetry and thermogravimetry, J. Therm. Anal. 38 (1992) 495-504.

[59] T. Nochaiya, W. Wongkeo, K. Pimraksa, A. Chaipanich, Microstructural, physical, and thermal analyses of Portland cement-fly ash-calcium hydroxide blended pastes, J. Therm. Anal. Calorim. 100 (2010) 101- 
108.

[60] I. Ismail, S.A. Bernal, J.L. Provis, R. San Nicolas, S. Hamdan, J.S.J. Van Deventer, Modification of phase evolution in alkali-activated blast furnace slag by the incorporation of fly ash, Cem. Concr. Compos. 45 (2014) 125-135. 


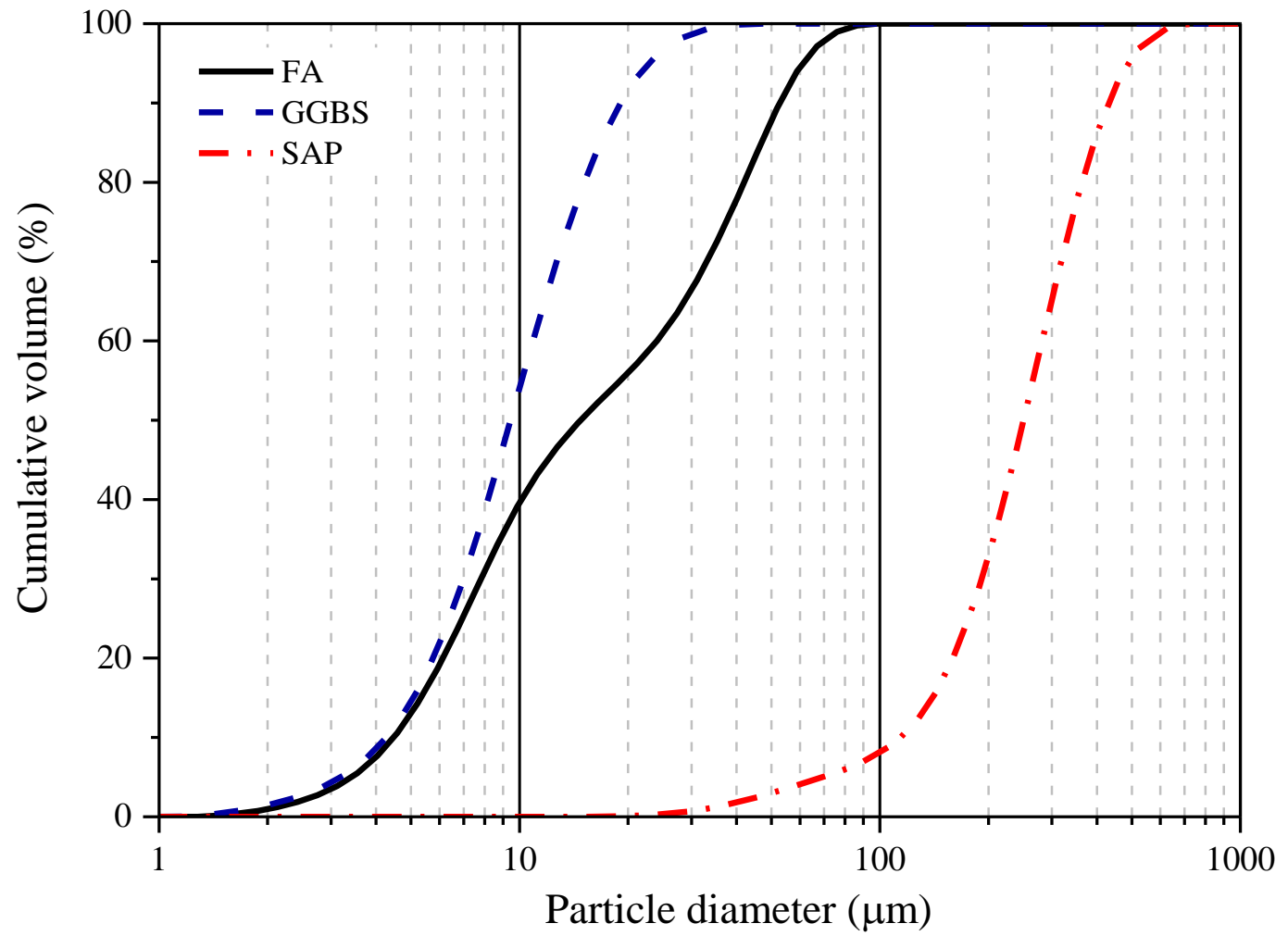

Fig. 1. Particle size distribution of FA, GGBS and SAP.

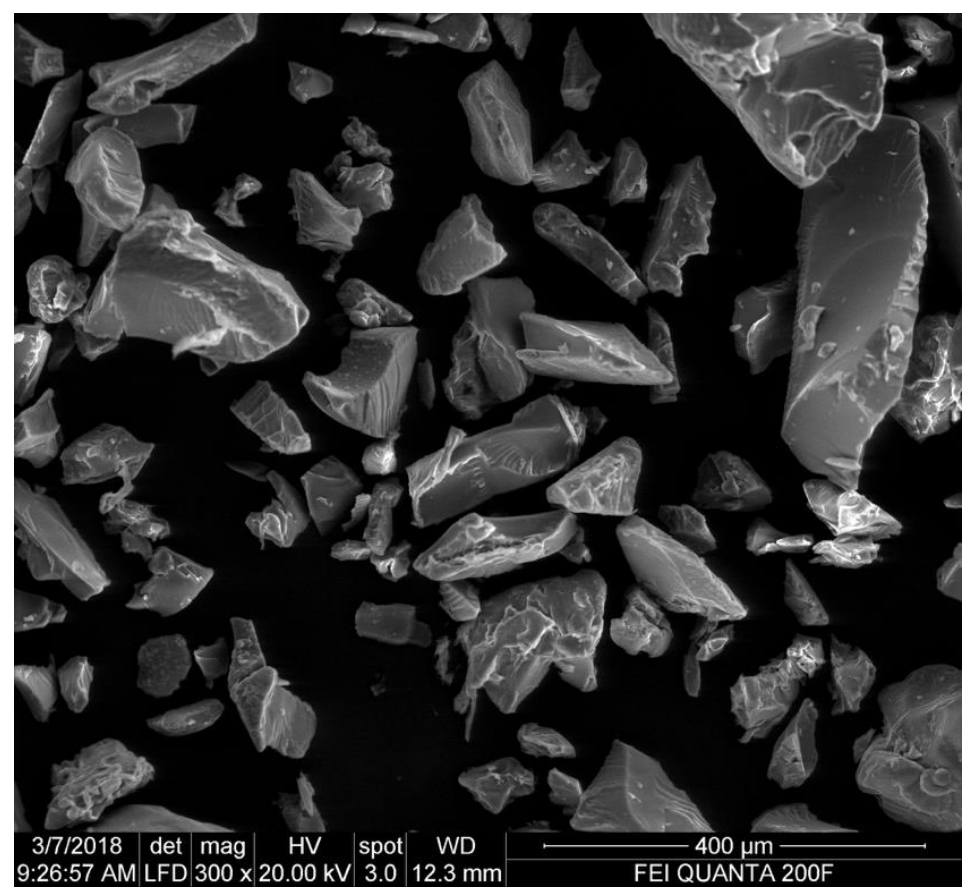

Fig. 2. SEM image of SAP sample in $300 \mathrm{x}$ magnification. 


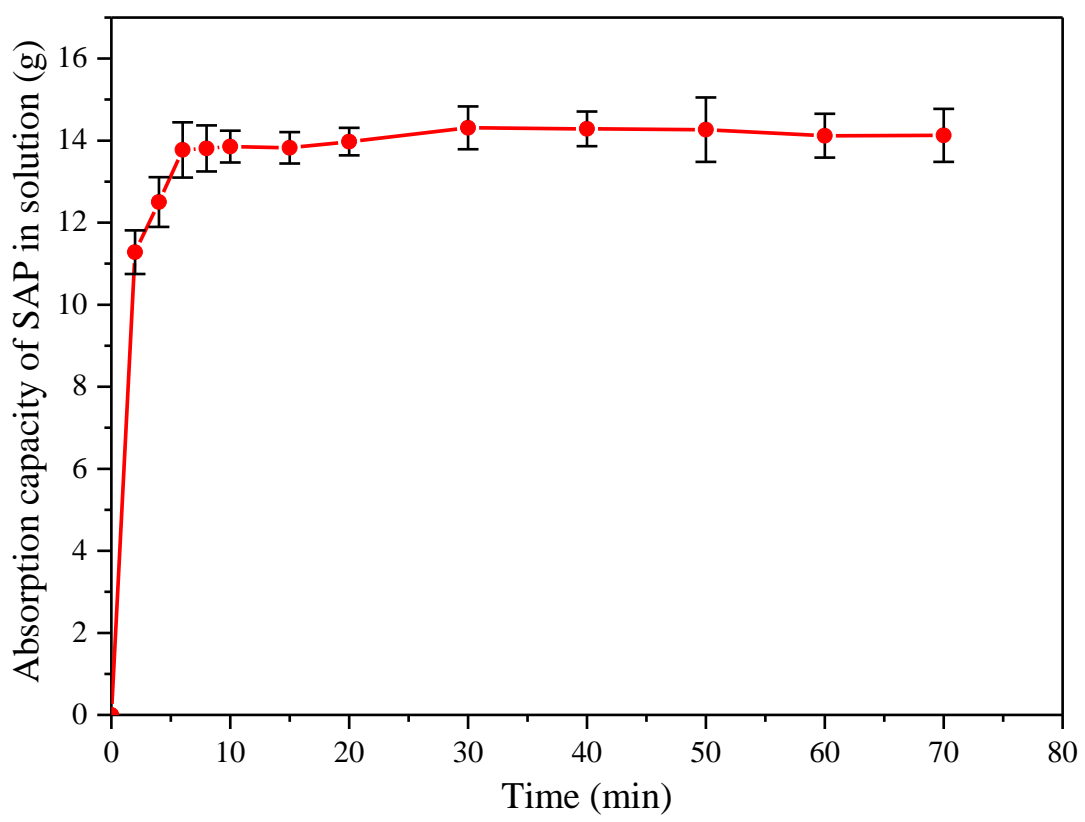

Fig. 3. Development of SAP sorption in solution in time.

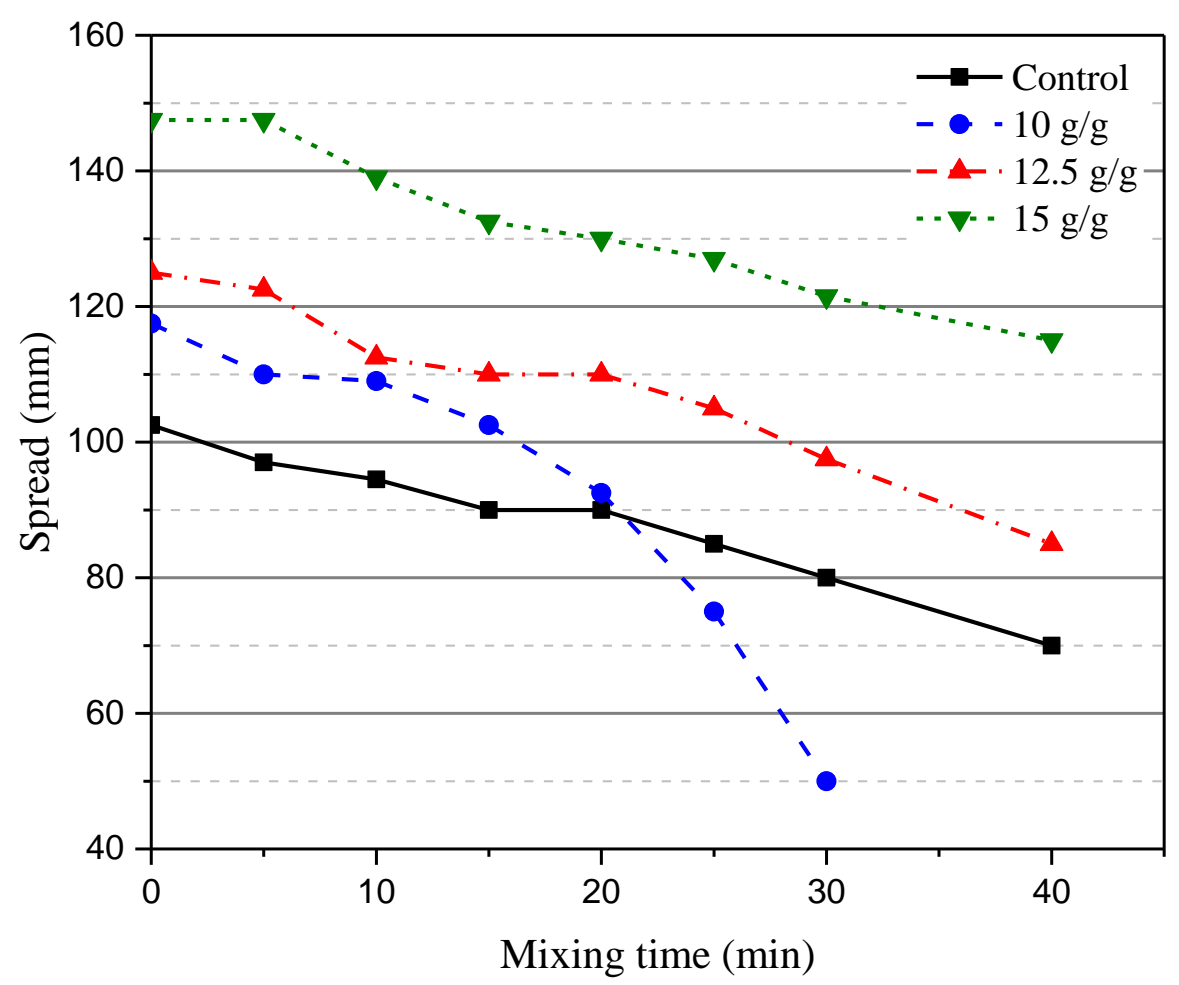

Fig. 4. Flowability of AAFS pastes with different water content against mixing time. 


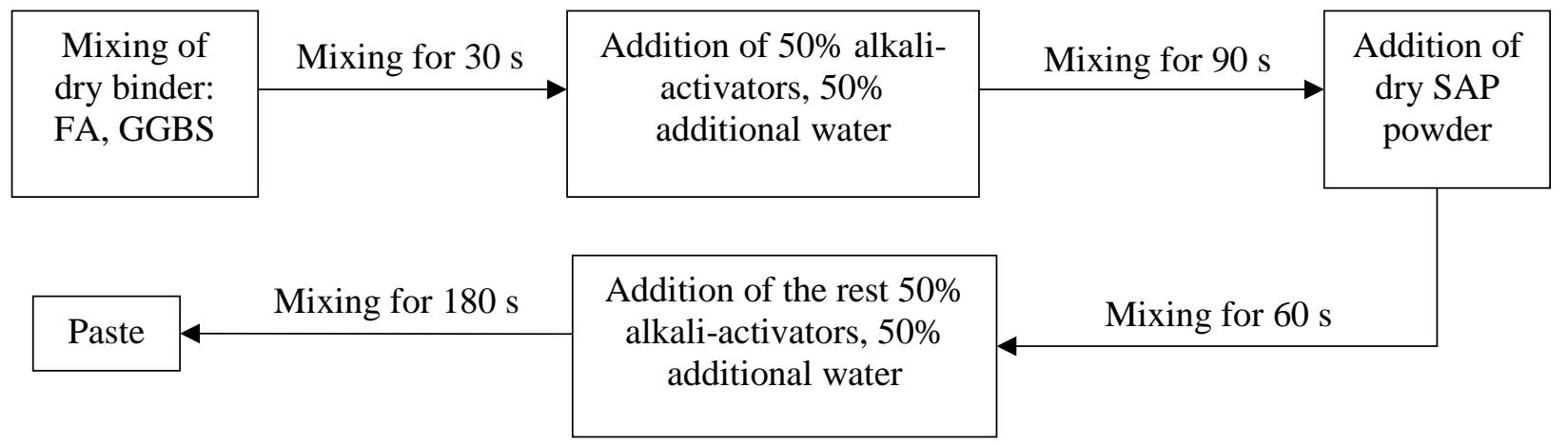

*For mixture of control samples without SAP, the total mixing time is reduced by $60 \mathrm{~s}$

Fig. 5. Mixing procedure for AAFS pastes.

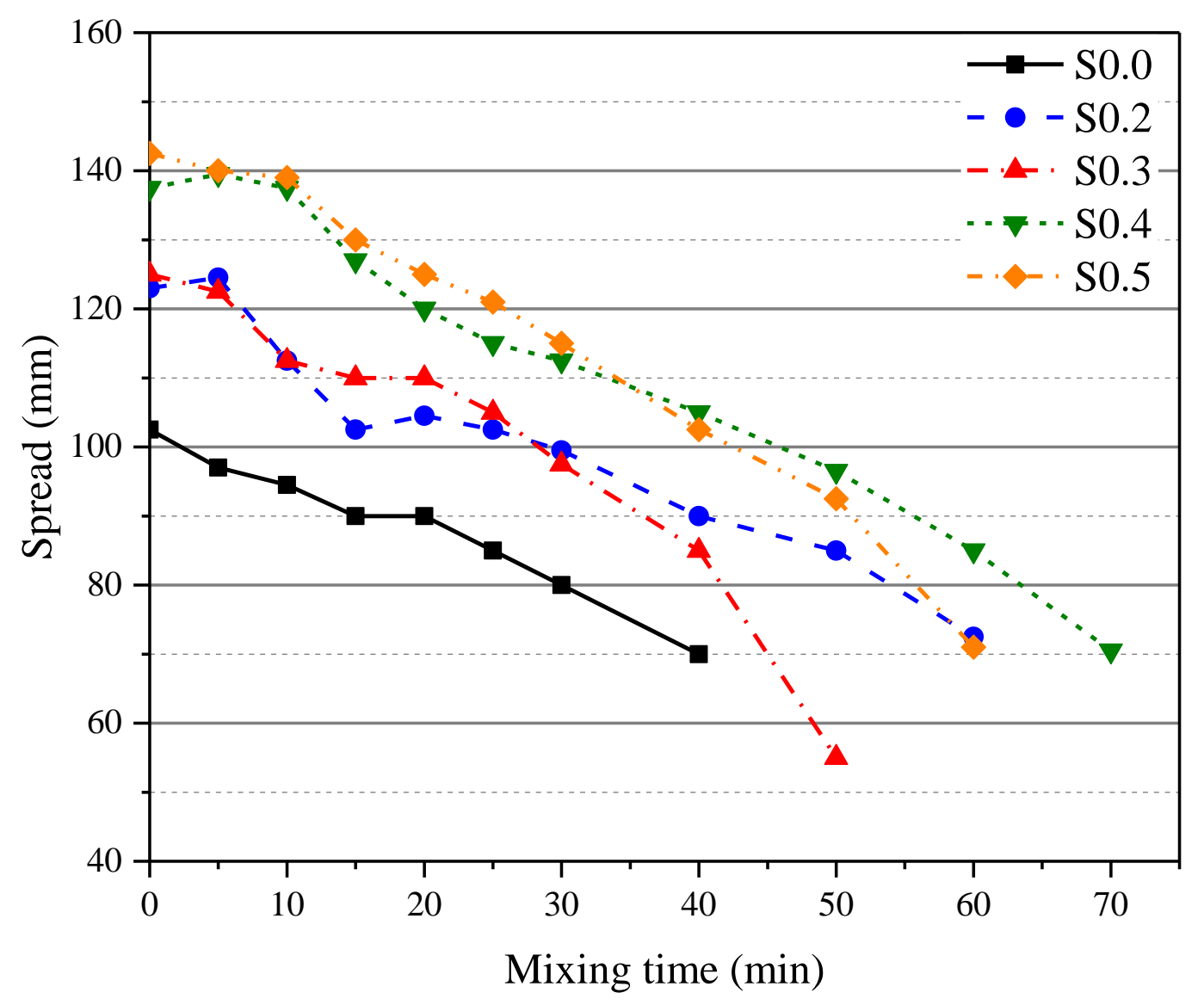

Fig. 6. Flowability of AAFS pastes with different SAP dosages against mixing time. 

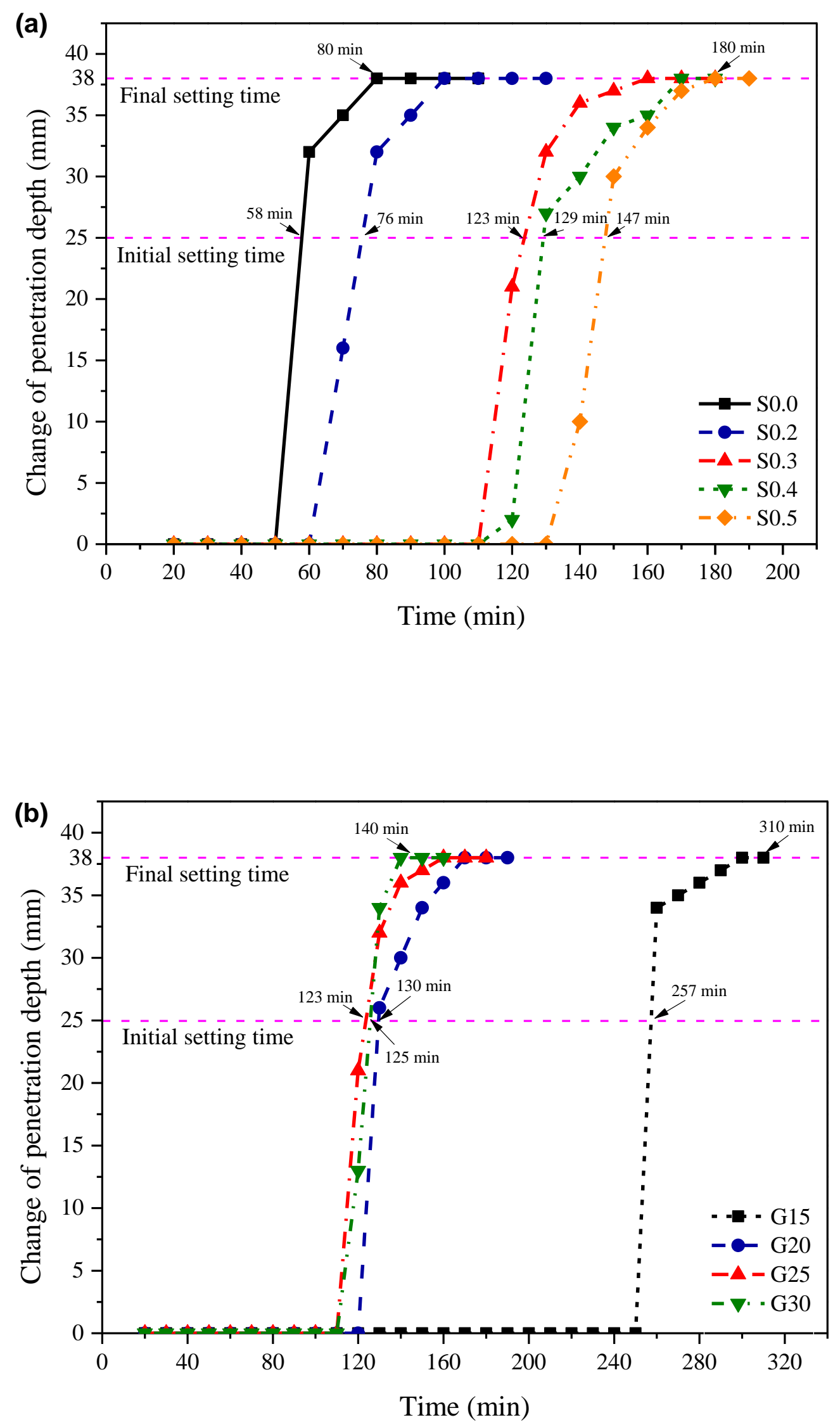

Fig. 7. Setting time of AAFS pastes with (a) different SAP dosages; (b) different slag content. 

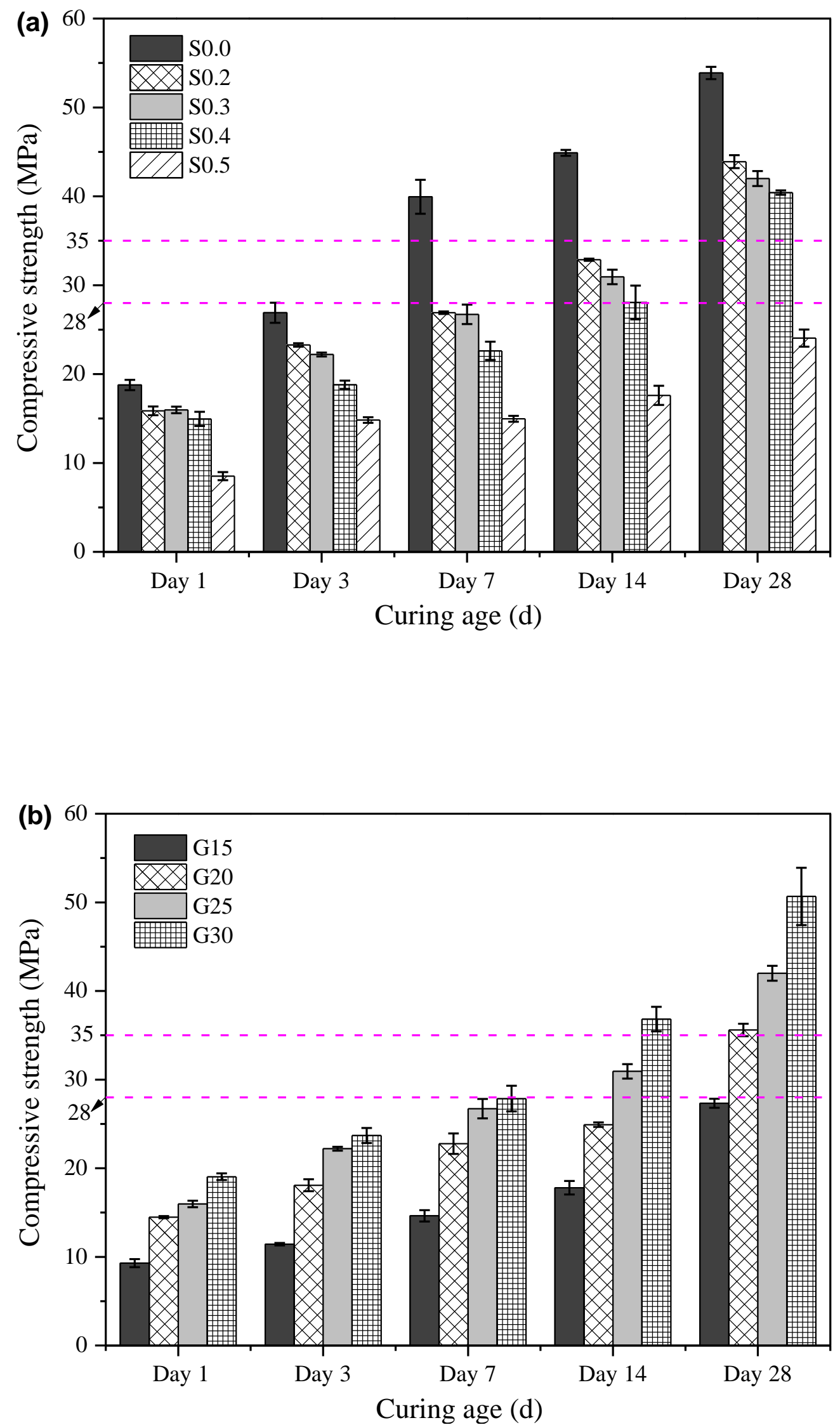

Fig. 8. Compressive strength of AAFS pastes with (a) different SAP dosages; (b) different slag content. 

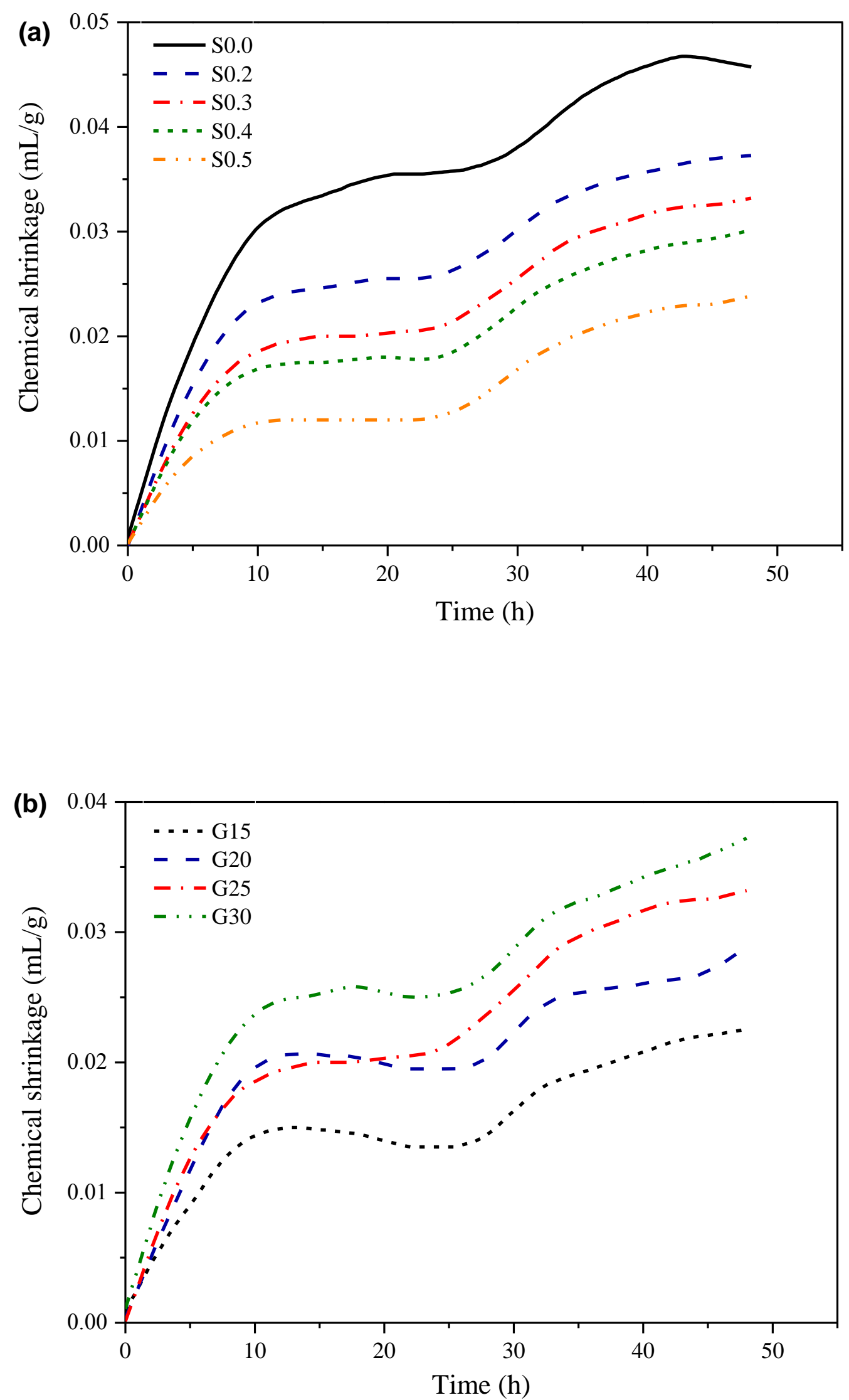

Fig. 9. Chemical shrinkage of AAFS pastes with (a) different SAP dosages; (b) different slag content. 

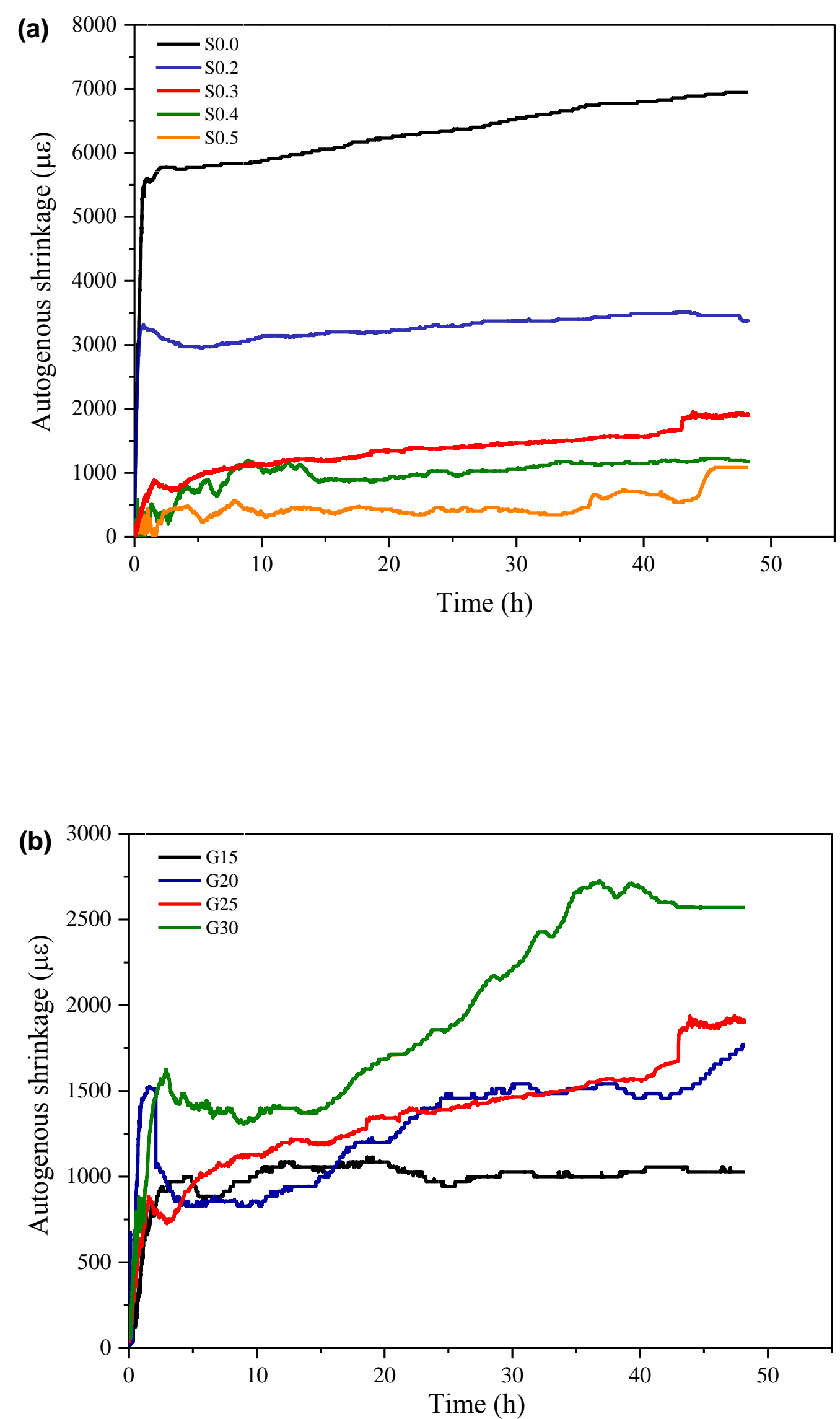

Fig. 10. Autogenous shrinkage of AAFS pastes with (a) different SAP dosages; (b) different slag content. 

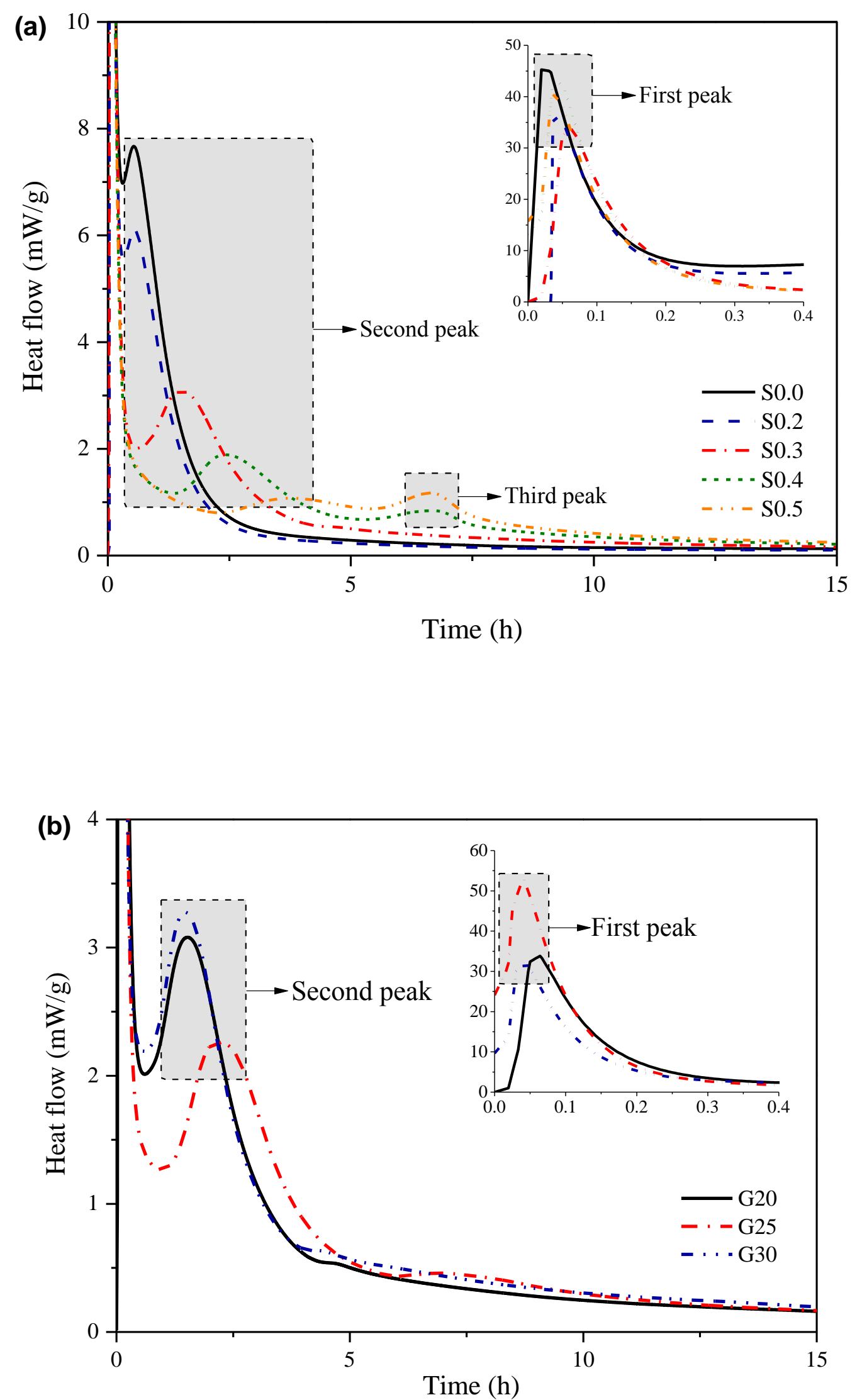

Fig. 11. Heat flow of AAFS pastes with (a) different SAP dosages; (b) different slag content. 

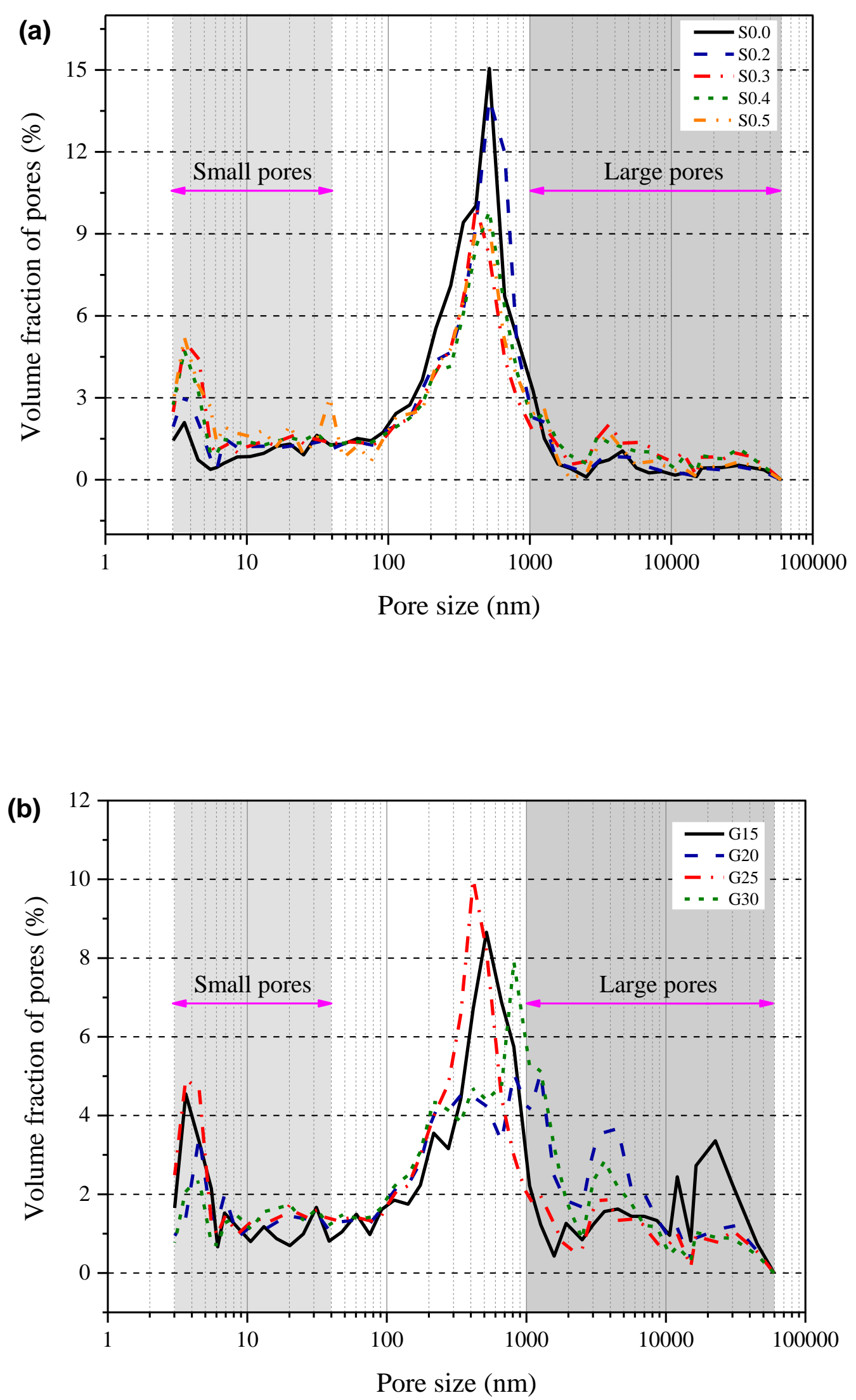

Fig. 12. Pore size distribution of AAFS pastes with (a) different SAP dosages; (b) different slag content. 


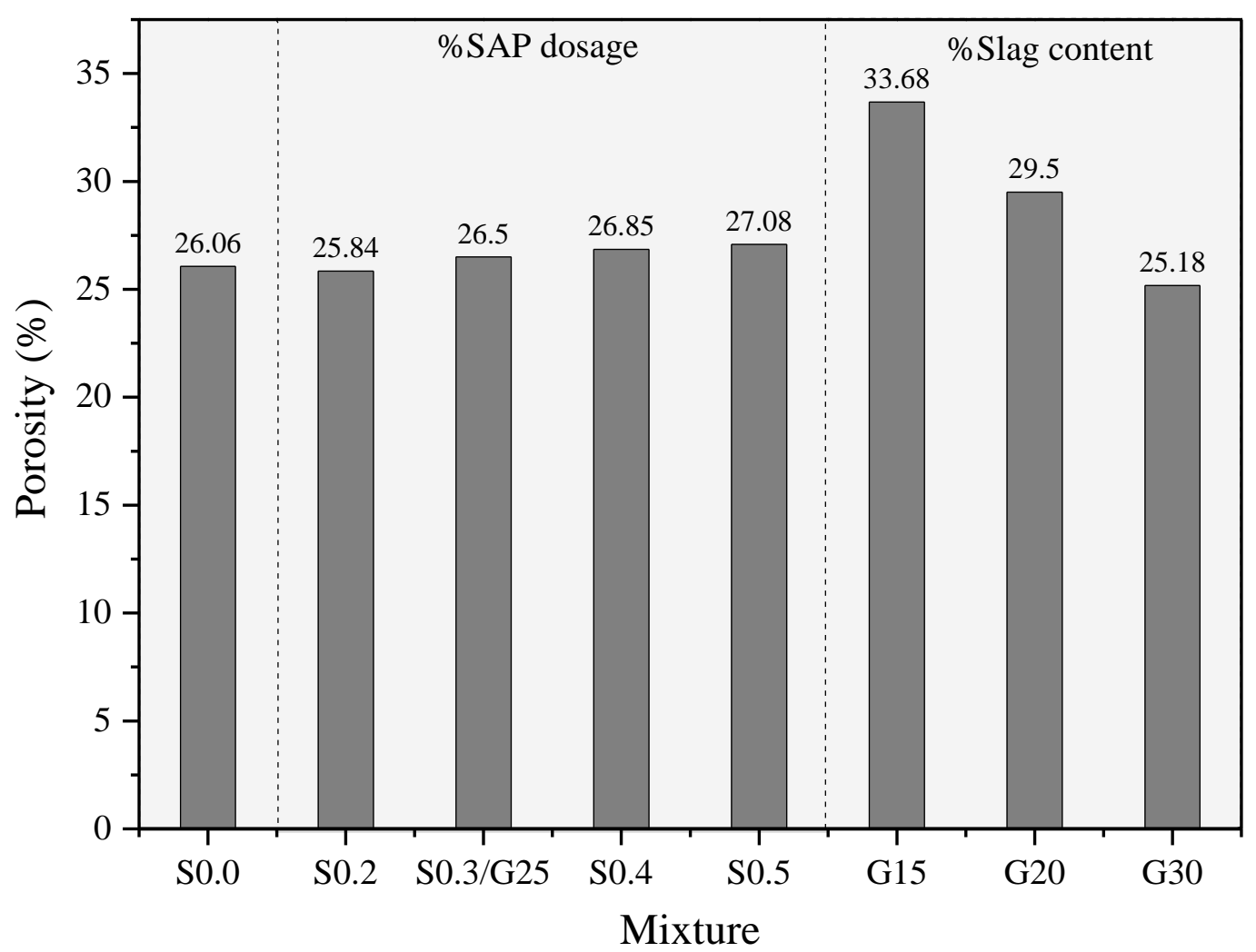

Fig. 13. Porosity of AAFS pastes with different SAP dosages and slag content. 

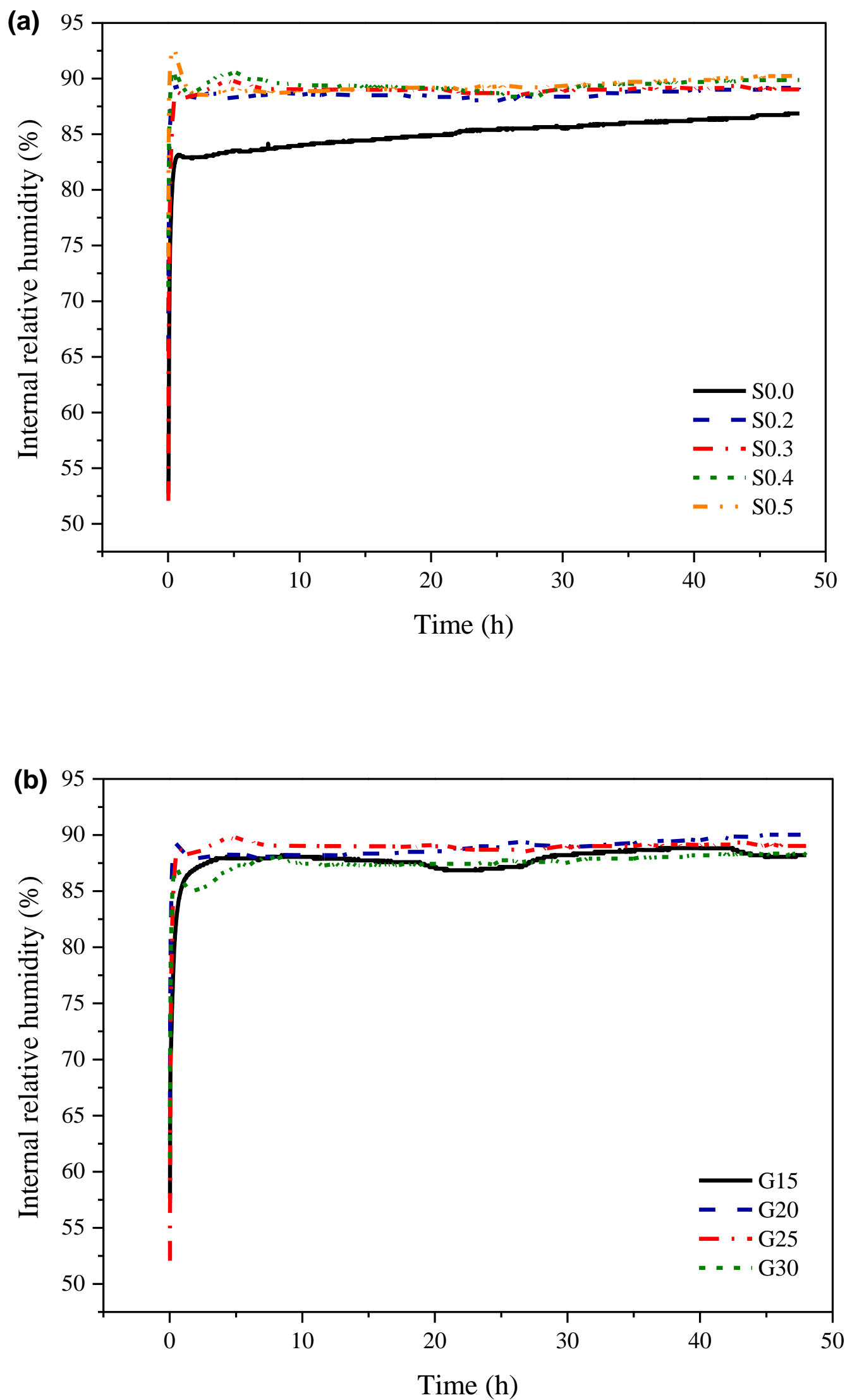

Fig. 14. Internal relative humidity of AAFS pastes with (a) different SAP dosages; (b) different slag content. 


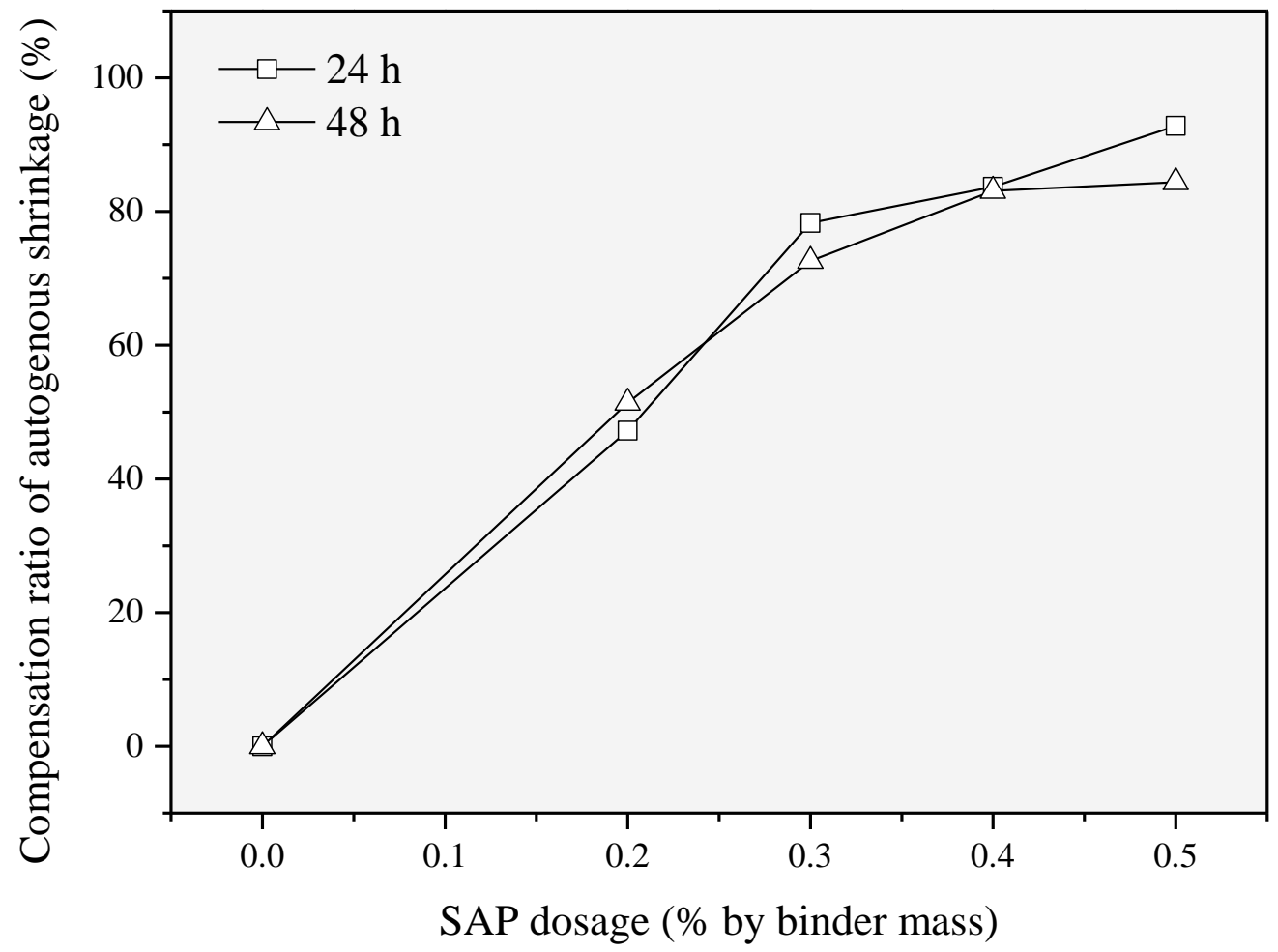

Fig. 15. Compensation ratio of autogenous shrinkage of AAFS pastes with different SAP dosages. 


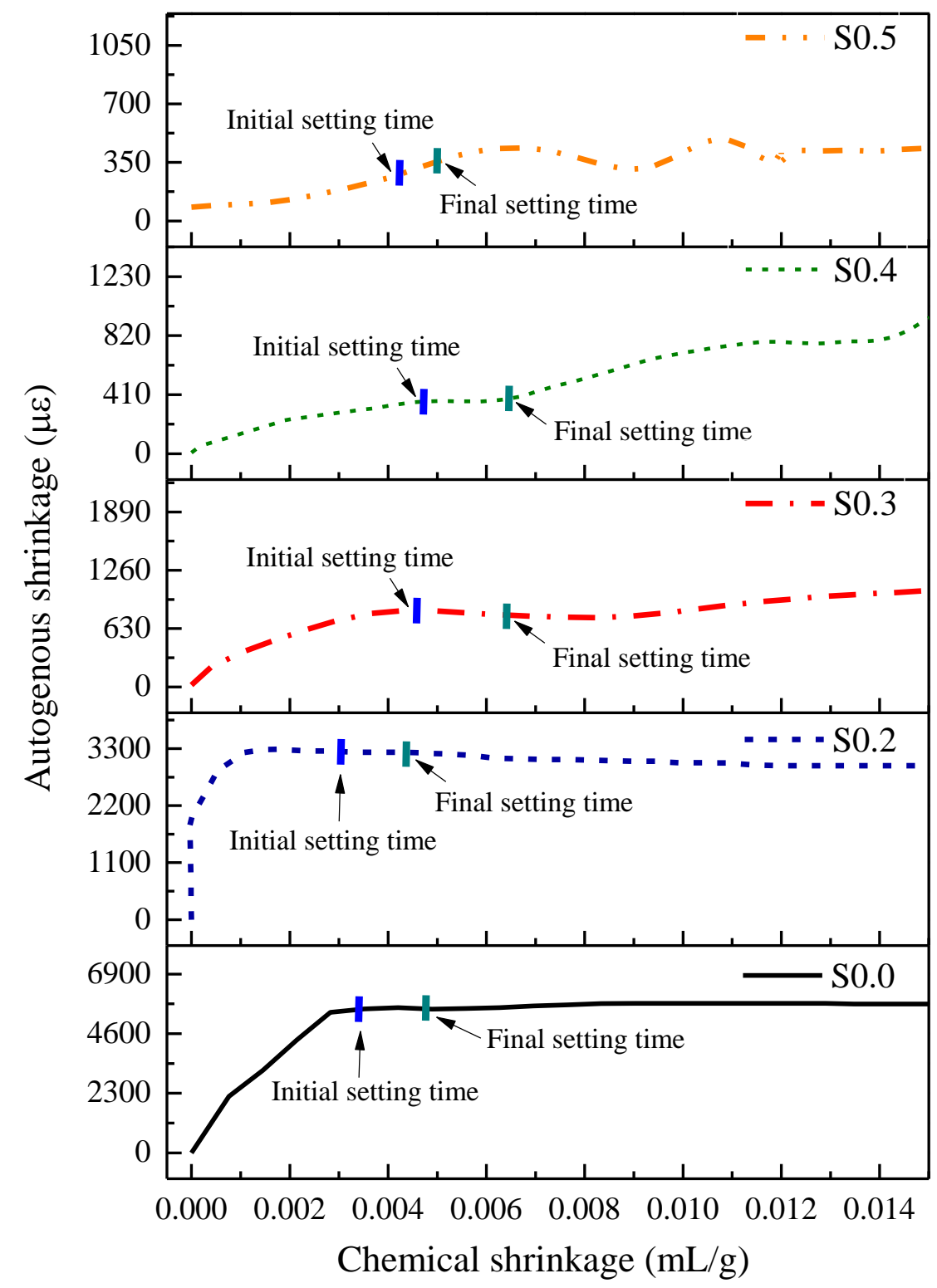

Fig. 16. Autogenous shrinkage against chemical shrinkage of AAFS pastes with different SAP dosages. 


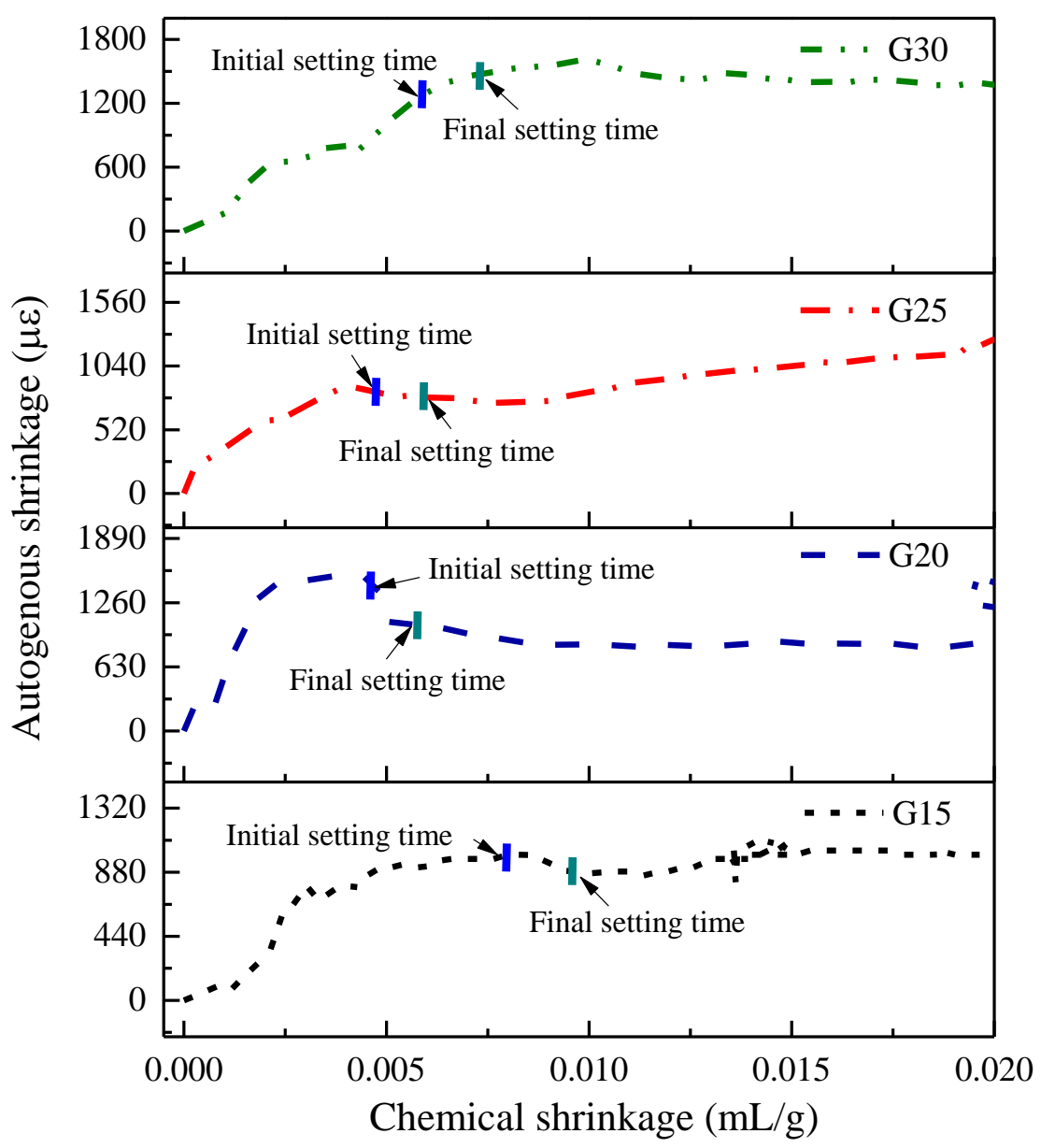

Fig. 17. Autogenous shrinkage against chemical shrinkage of AAFS pastes with different slag content. 


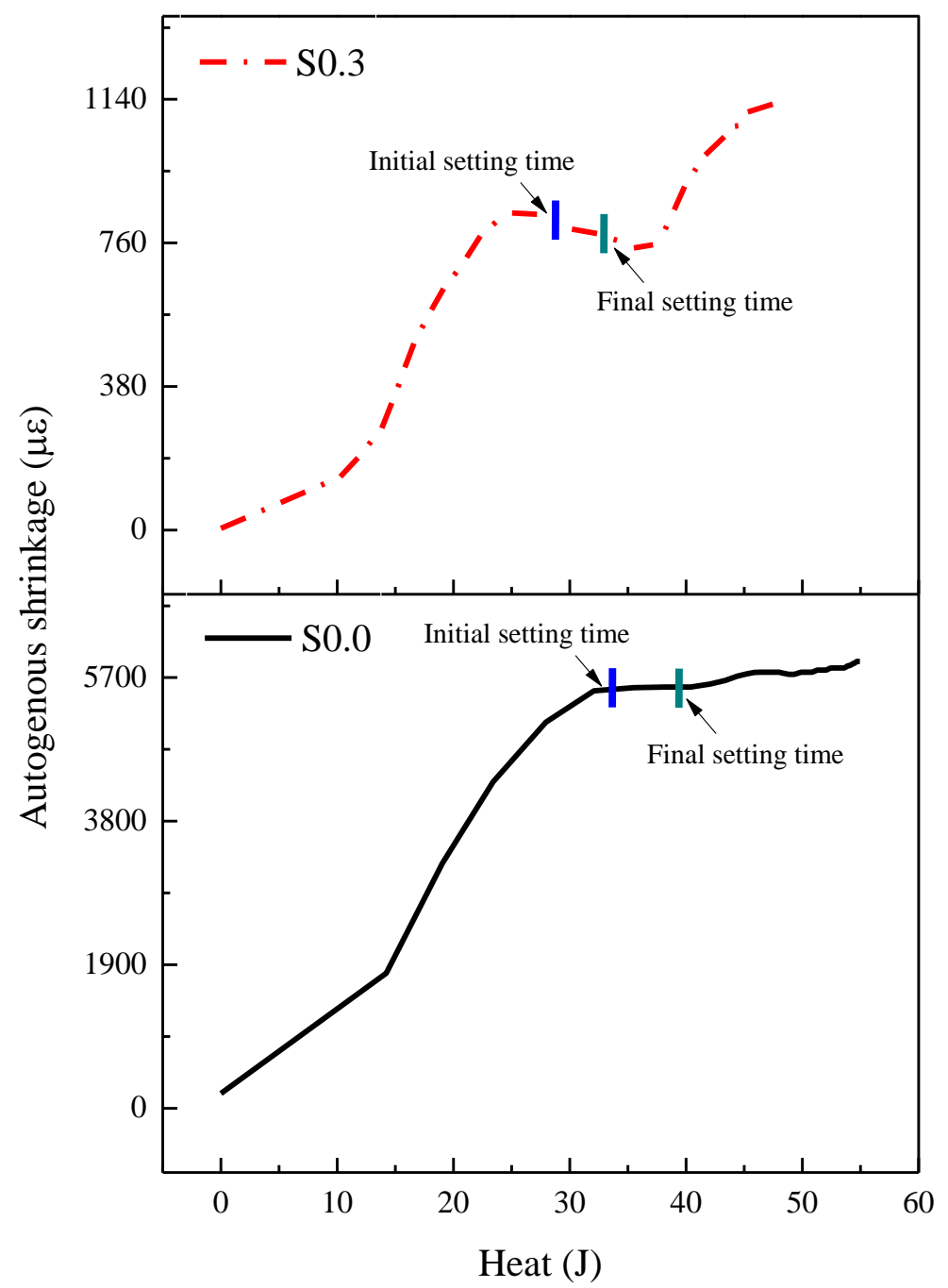

Fig. 18. Autogenous shrinkage against cumulative heat of AAFS pastes with and without SAP. 


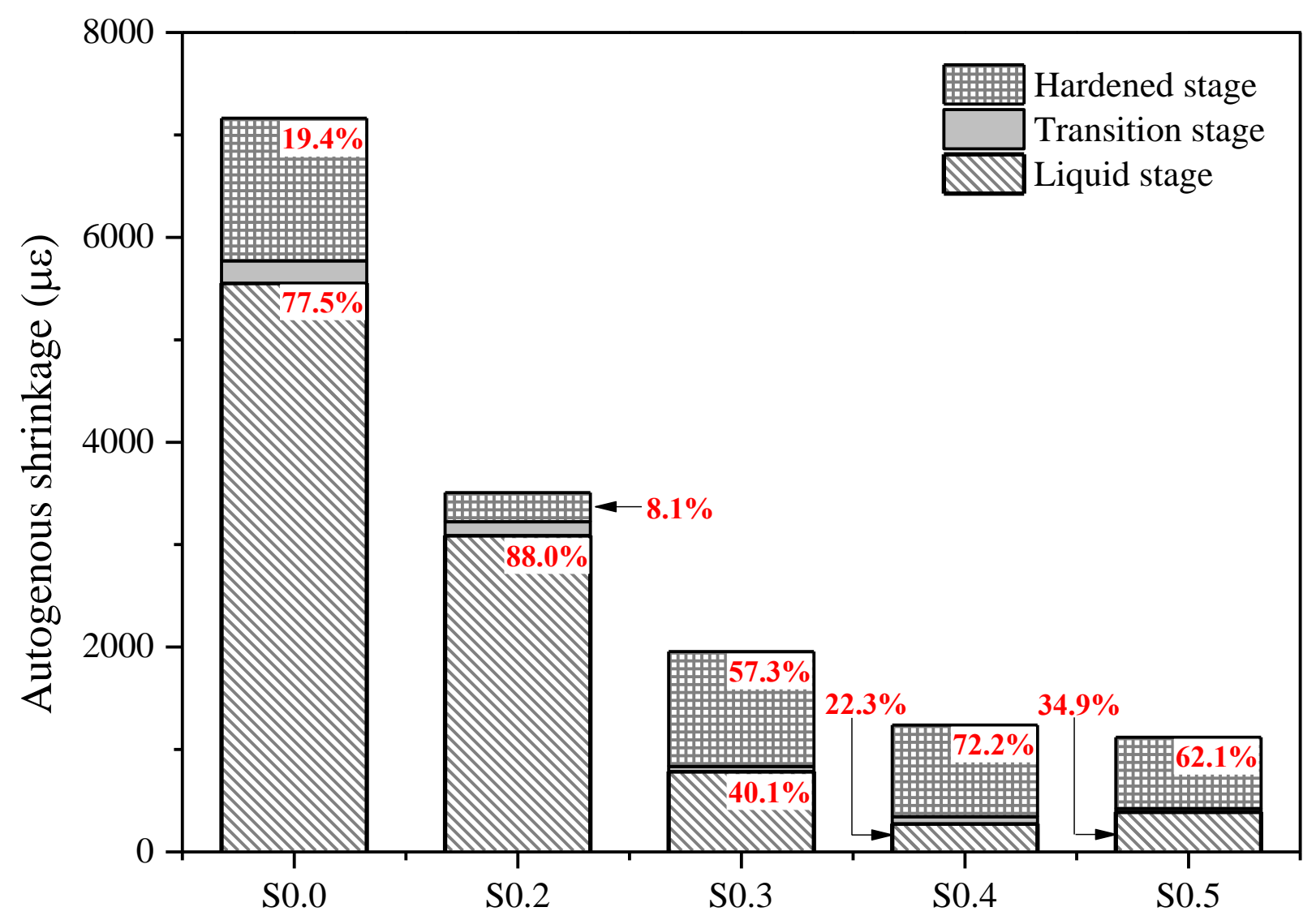

Fig. 19. Autogenous shrinkage fractions of AAFS pastes with different SAP dosages. 
Table 1 Chemical compositions (wt.\%) of FA and GGBS

\begin{tabular}{ccccccccccc}
\hline Oxide & $\mathrm{SiO}_{2}$ & $\mathrm{Al}_{2} \mathrm{O}_{3}$ & $\mathrm{CaO}$ & $\mathrm{MgO}$ & $\mathrm{K}_{2} \mathrm{O}$ & $\mathrm{Fe}_{2} \mathrm{O}_{3}$ & $\mathrm{TiO}_{2}$ & $\mathrm{Na}_{2} \mathrm{O}$ & $\mathrm{SO}_{3}$ & $\mathrm{MnO}$ \\
\hline FA & 53.24 & 26.42 & 3.65 & 9.55 & 2.57 & 1.65 & 0.86 & 0.76 & 0.56 & - \\
GGBS & 34.30 & 15 & 39.40 & 8 & 0.38 & 0.40 & 0.70 & 0.45 & - & 0.50 \\
\hline
\end{tabular}

Table 2 Specific gravity of each ingredient

\begin{tabular}{cccccc}
\hline & FA & GGBS & SS & SH & SPs \\
\hline Specific gravity & 2.25 & 2.9 & 1.309 & 1.45 & 1.08 \\
\hline
\end{tabular}

Table 3 Typical characteristics of selected SAP product

\begin{tabular}{ccccc}
\hline \multicolumn{2}{c}{ Product characteristics } & & \multicolumn{2}{c}{ Maximal absorption } \\
\cline { 1 - 2 } \cline { 5 - 5 } Appearance & $\begin{array}{c}\text { Very fine white } \\
\text { powder }\end{array}$ & & $\Delta \mathrm{m} / \mathrm{m}$ de-ionised water (pH 6.5) & $400 \mathrm{~g} / \mathrm{g}$ SAP \\
Moisture content & $10 \%$ & $\Delta \mathrm{m} / \mathrm{m}$ tap water $(\mathrm{pH}$ 6.8) & $200 \mathrm{~g} / \mathrm{g} \mathrm{SAP}$ \\
$\begin{array}{c}\text { Approximate bulk } \\
\text { density }\end{array}$ & $900 \mathrm{~kg} / \mathrm{m}^{3}$ & & $\Delta \mathrm{m} / \mathrm{m}$ modelled reaction environment (pH & $14 \mathrm{~g} / \mathrm{g} \mathrm{SAP}$ \\
Solubility & Insoluble in water & & $\Delta \mathrm{m} / \mathrm{m}$ during AAFS paste mixing (pH 13) & $12.5 \mathrm{~g} / \mathrm{g} \mathrm{SAP}$ \\
\hline
\end{tabular}

Table 4 Mix proportions of AAFS pastes

\begin{tabular}{cccccccccc}
\hline Mix No. & Designation & $\begin{array}{c}\text { Binder } \\
\left(\mathrm{kg} / \mathrm{m}^{3}\right)\end{array}$ & $\begin{array}{c}\text { FA } \\
\left(\mathrm{kg} / \mathrm{m}^{3}\right)\end{array}$ & $\begin{array}{c}\text { GGBS } \\
\left(\mathrm{kg} / \mathrm{m}^{3}\right)\end{array}$ & $\begin{array}{c}\mathrm{SS} \\
\left(\mathrm{kg} / \mathrm{m}^{3}\right)\end{array}$ & $\begin{array}{c}\mathrm{SH} \\
\left(\mathrm{kg} / \mathrm{m}^{3}\right)\end{array}$ & $\begin{array}{c}\mathrm{SPs} \\
\left(\mathrm{kg} / \mathrm{m}^{3}\right)\end{array}$ & $\begin{array}{c}\mathrm{SAP} \\
\left(\mathrm{kg} / \mathrm{m}^{3}\right)\end{array}$ & $\begin{array}{c}\text { Water } \\
\left(\mathrm{kg} / \mathrm{m}^{3}\right)\end{array}$ \\
\hline 0 & $\mathrm{~S} 0.0$ & 400 & 300 & 100 & 106.5 & 53.5 & 4 & 0 & 0 \\
1 & $\mathrm{~S} 0.2$ & 400 & 300 & 100 & 106.5 & 53.5 & 4 & 0.8 & 10 \\
2 & $\mathrm{~S} 0.3 / \mathrm{G} 25$ & 400 & 300 & 100 & 106.5 & 53.5 & 4 & 1.2 & 15 \\
3 & $\mathrm{~S} 0.4$ & 400 & 300 & 100 & 106.5 & 53.5 & 4 & 1.6 & 20 \\
4 & $\mathrm{~S} 0.5$ & 400 & 300 & 100 & 106.5 & 53.5 & 4 & 2 & 25 \\
5 & $\mathrm{G} 15$ & 400 & 340 & 60 & 106.5 & 53.5 & 4 & 1.2 & 15 \\
6 & $\mathrm{G} 20$ & 400 & 320 & 80 & 106.5 & 53.5 & 4 & 1.2 & 15 \\
7 & $\mathrm{G} 30$ & 400 & 280 & 120 & 106.5 & 53.5 & 4 & 1.2 & 15 \\
\hline
\end{tabular}

